\title{
ACUTE ENVIRONMENTAL TOXICITY AND \\ PERSISTENCE OF DEM, A CHEMICAL AGENT SIMULANT: DIETHYL MALONATE
}

\author{
Final Report
}

\author{
Dominic A. Cataldo, Ph.D. \\ Michael W. Ligotke, M.S. \\ Scott D. Harvey, Ph.D. \\ Robert J. Fellows, Ph.D. \\ Shu-mei W. Li, M.S. \\ Peter Van Voris, Ph.D. \\ Randall S. Wentsel, Ph.D.
}

\begin{abstract}
May 1990
Supported by:

U.S. Army Armament, Munitions \& Chemical Command Aberdeen Proving Ground, MD 21010-5423
\end{abstract}

Project Order No. 0311-1460

\author{
Pacific Northwest Laboratory \\ Richland, Washington 99352 \\ Operated for the U.S. Department of Energy \\ by Battelle Memorial Institute
}

Approved for public release;

distribution unlimited 


\title{
DISCLAIMER
}

This reporl was prepared as an account of work sponsored by an agency of the United States Government. Neither the United States Government nor any agency thereof, nor Battelle Memorial Institute, nor any of their employees, makes any warranty, expressed or implied, or assumes any legal liability or responsibility for the accuracy, completeness, or usefulness of any information, apparatus, product, or process disclosed, or represents that its use would not infringe privately owned rights. Reference herein to any specific commercial product, process, or service by trade name, trademark, manufacturer, or otherwise does not necessarily constitute or imply its endorsement, recommendation, or favoring by the United States Government or any agency thereof, or Battelle Memorial Institute. The views and opinions of authors expressed herein do not necessarily state or reflect those of the United States Governmerit or any agency thereof.

\author{
PACIFIC NORTHWEST LABORATORY \\ operated by \\ BATTELLE MEMORIAL INSTITUTE \\ for the \\ UNITED STATES DEPARTMENT OF ENERGY \\ under Contract DE-ACO6-76RLO 1830
}

Printed in the United States of America

\author{
Available to DOE and DOE contractors from the \\ Office of Scientific and Technical Information, P.O. Box 62, Oak Ridge, TN 37831; \\ prices available from (615) 576-8401. FTS 626-8401.
}

Available to the public from the National Technical Information Service, U.S. Depariment of Commerce, 5285 Port Royal Rd., Springfield, VA 22161.

Alt references cited in this document are public information, but may not be available from public sources (e.g., some foreign travel reports). These references may be made available to interested readers from the author of the specific reference or from:

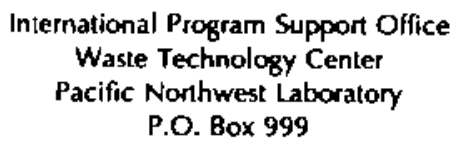

(509) 376-0933 or

(509) 376-5059 


\title{
ACUTE ENVIRONMENTAL TOXICITY AND PERSISTENCE OF DEM, A CHEMICAL AGENT SIMULANT: DIETHYL MALONATE
}

Final Report

\author{
Dominic A. Cataldo, Ph.D \\ Michael W. Ligotke, M.S \\ Scott D. Harvey, Ph.D \\ Robert J. Fellows, Ph.D \\ Shu-mei W. Li, M.S. \\ Peter Van Voris, Ph.D \\ Randall S. Wentsel, Ph.D.
}

\section{May 1, 1990}

\section{Supported by:}

\section{U.S. Army Armament, Munitions \& Chemical Command Aberdeen Proving Ground, MD 21010-5423 \\ Project Number 0311-1460}

\section{Pacific Northwest Laboratory}

Richland, Washington 99352

Operated for the U.S. Department of Energy

by Battelle Memorial Institute

\section{Project Officer: Randall S. Wentsel, Ph.D. \\ U.S. Army Chemical Research, Development and Engineering Center Aberdeen Proving Ground, MD 21010-5423}

Approved for Public Release; distribution unlimited

\footnotetext{
The findings of this report are not to be construed as official Department of the Army position unless so designated by other authorized documents
} 

Acute Environmental Toxicity and Persistence of DEM, a Chemical Agent Simulant: Diethyl Malonate

6. AUTHOR(S)

Dominic Cataldo, Ph.D.; Michael W. Ligotke, M.S.; Scott Harvey, Ph.D.; Robert Fellows, Ph.D.; Shu-Mei W. Li, M.S.; Peter Van Voris, Ph. D.: Randall S, Wentsel, Ph.D. 7. PERFCRMING ORGANIZATICN SAAME(S) AND ADORESSIE引i

Pacific Northwest Laboratory

P. 0. Box 999

Richland, WA. 99352

9. SPON5ORING ; MONITOARIVG AGEIVCY NAME(ST AंHD ACDRESJ(ES)

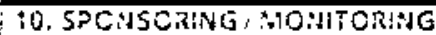

U.S. Army Armament Munitions Chemical Command

Aberdeen Proving Ground, MD 21010-5423

i. SUPPLEMENTARY NOTES

Results indicate that the vapor pressure of DEM is high enough to result in mixed gas and liquid phases. Vapor dominated in the low dose test, while in the high dose test, liquid droplets dominated. This affected the overall rate of deposition to surfaces. Deposition velocities for DEM to soil surfaces ranged from 0.04 to $0.2 \mathrm{~cm} / \mathrm{sec}$, for low and high air concentrations, respectively. For foliar surfaces, deposition velocities ranged from $0.0002 \mathrm{~cm} / \mathrm{sec}$ at low air concentrations to $0.05 \mathrm{~cm} / \mathrm{sec}$ at high dose levels.

The volatility of DEM results in a rapid loss from soil and foliar surfaces. The residence times or half-lives of DEM deposited to soils was $2 \mathrm{~h}$ for the fast component and 5 to $16 \mathrm{~h}$ for the residual material. For foliar surfaces, the half-life of the short residence time component ranged form 1 to $3 \mathrm{~h}$, while the longer time component had halt-times of 16 to $242 \mathrm{~h}$. Volatilization and other depuration mechanisms reduce surface contaminant levels in both soils and foliage to less than $1 \%$ of initial dose within $96 \mathrm{~h}$.

\begin{tabular}{|c|c|c|c|}
\hline \multicolumn{3}{|l|}{ 14. SUBJECT TERMS } & $\begin{array}{l}\text { 15. NUMBER OF PAGES } \\
\text { 16. PRICE COOE } \\
\end{array}$ \\
\hline
\end{tabular}


DEM is not phytotoxic at foliar mass loading levels of less than $10 \mu \mathrm{g} / \mathrm{cm}^{2}$. However, severe damage is evident at mass loading levels in excess of $17 \mu \mathrm{g} / \mathrm{cm}^{2}$. Tall fescue and sagebrush were more affected than was short-needle pine, however, mass loading levels were markedly different. Regrowth of tall fescue indicated that the effects of DEM are residual, and growth rates are affected at higher mass loadings through the second harvest.

Results from in vitro testing of DEM indicated concentrations below $500 \mu \mathrm{g} / \mathrm{g} \mathrm{dry}$ soil generally did not negatively impact soil microbial activity. In fact, Palouse soil dehydrogenase activity was initially enhanced by the addition of DEM at 25 to $500 \mu \mathrm{g} / \mathrm{g}$. Short-term effect of DEM (2-3 days incubation) was more profound on soil dehydrogenase activity (EcD50 $\approx 2500$ $\mu \mathrm{g} / \mathrm{g}$ ) than on soil phosphatase activity (EcD50 > 2500 $\mu \mathrm{g} / \mathrm{g}$ ), indicating soil dehydrogenase is more susceptible to DEM than soil phosphatase. However, no enzyme inhibition or enhancement was observed after 28 days incubation, indicating the effect is transient in nature with a possibility of recovery.

Results of the earthworm bioassay indicate survival to be 86 and $66 \%$ at soil doses of 107 and 204 gEM/cm², respectively. 


\section{FOREWORD}

Opinions, interpretations, conclusions and recommendations are those of the author and are not necessariiy endorsed by the U.S. Army.

\section{$X$} Where copyrighted material is quoted. permission has been obtained to use such materiat.

$\mathrm{X}$ Where material from documents designated for limited distribution is quoted. permission has been obtained to use the material.

$X$

Citations of commercial organizations and trade names in this report do not constitute an official Department of the Army endorsement or approval of the products or services of these organizations.

$x$ In conducting research using animals, the investigator ( $s$ ) adhered to the "Guide for the Care and Use of Laboratory Animals." prepared by the Committee on Care and Use of Laboratory Animals of the Institute of Laboratory Animal Resources. National Research Council (NIH Publication No. 86-23, Revised 1985.)

$X$ For the protection of human subjects, the investigator ( $s$ ) have adhered to policies of applicable Federa? Law 45CFR46.

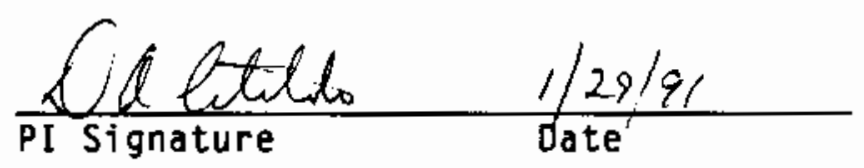


, 


\section{PREFACE}

The use of trade names or manufacturer's names in this report does not constitute an official endorsement of any products. This report may not be cited for purposes of advertisement.

Reproduction of this report in whole or in part is prohibited except with permission of the Commander, U. S. Army Chemical Research, Development, and Engineering Center, ATTN: SMCCR-SPS-T, Aberdeen Proving Ground, Maryland. Technical Information Services are authorized to reproduce the document for U. S. government purposes.

Acknowledgements:

The authors wish to thank Don C. Klopher and Barbara A. O'Brien for technical support during this project. 


\section{EXECUTIVE SUMMARY}

The purpose of the following chemical simulant studies is to assess the potential acute environmental effects and persistence of diethyl malonate (DEM). Studies were designed to provide baseline data related to the effects of DEM terrestrial organisms, namely plant, soil microorganisms and earthworms, and to assess the relative depuration from environmental surfaces. Deposition velocities for DEM to soil surfaces ranged from 0.04 to $0.2 \mathrm{~cm} / \mathrm{sec}$, for low and high air concentrations. For foliar surfaces, deposition velocities ranged from 0.0002 $\mathrm{cm} / \mathrm{sec}$ at low air concentrations to $0.05 \mathrm{~cm} / \mathrm{sec}$ for high dose levels. Collection efficiency was lowest for short-needle pine and greatest for sagebrush and tall fescue.

DEM deposited to soil and foliar surfaces is rapidly lost through volatization processes. The residence times or half-lives of DEM deposited to soils was $2 \mathrm{~h}$ for the fast component and 5 to $16 \mathrm{~h}$ for the residual material. DEM deposited to foliar surfaces also exhibited biphasic depuration. The half-life of the short residence time component ranged from 1 to $3 \mathrm{~h}$, while the longer time component had half-times of 16 to $242 \mathrm{~h}$. Volatilization and other depuration mechanisms reduce surface contaminant levels in both soils and foliage to less than $1 \%$ of initial dose within $96 \mathrm{~h}$.

DEM is not phytotoxic at foliar mass loading levels of less than $10 \mu \mathrm{g} / \mathrm{cm}^{2}$. However, severe damage is evident at mass loading levels in excess of $17 \mu \mathrm{g} / \mathrm{cm}^{2}$. Tall fescue and sagebrush were more affected than was short-needle pine, however, mass loading levels were markedly different. Regrowth of tall fescue indicated that the effects of DEM are residual, and growth rates are affected only at higher mass loadings through the second harvest. At higher dose levels in vitro studies failed to indicate any effects of DEM on photosynthesis/respiration or electron transport at solution concentrations of $100 \mu \mathrm{g} / \mathrm{mL}$.

Results from in vitro testing of DEM indicated concentrations below $500 \mu \mathrm{g} / \mathrm{g}$ dry soil generally did not negatively impact soil microbial activity. Short-term effects of DEM were more profound on soil dehydrogenase activity than on soil phosphatase activity, indicating soil dehydrogenase is more susceptible to DEM than soil phosphatase. However, no enzyme inhibition or enhancement was observed after 28 days incubation, indicating the effect is transient in nature with a possibility of recovery.

Resuits of the earthworm bioassay indicate survival to be 86 and $66 \%$ at soil doses of 107 and $204 \mu \mathrm{gEM} / \mathrm{cm}^{2}$, respectively. At higher dose level, activity or mobility was judged to be affected in over $50 \%$ of the individuals. 



\begin{tabular}{|c|c|c|c|}
\hline & & & Page \\
\hline & & OCUMENT PAGE. & $\mathrm{iii}$ \\
\hline & & & $\checkmark$ \\
\hline & & & vi \\
\hline & & E SUMMARY.. & vii \\
\hline 1.0 & INTR & 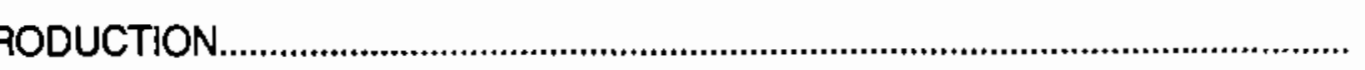 & 1.1 \\
\hline & 1.1 & CHEMICAL PROPERTIES. & 1.3 \\
\hline & 1.2 & ENVIRONMENTAL FATE AND EFFECTS & 1.3 \\
\hline & & OBJECTIVES & 1.3 \\
\hline 2.0 & MAT & TERIALS AND METHODS & 2.1 \\
\hline & 2.1 & EXPOSURE SYSTEM........................ & 2.1 \\
\hline & 2.2 & 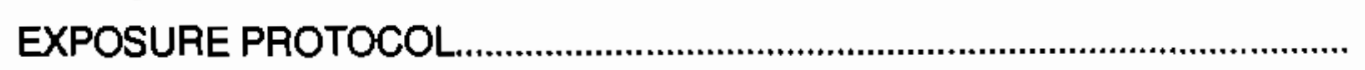 & 2.3 \\
\hline & 2.3 & AEROSOL GENERATION & 2.4 \\
\hline & 2.4 & 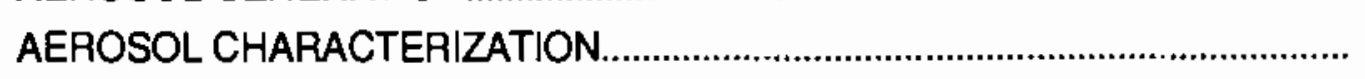 & 2.6 \\
\hline & & 2.4.1 Bubbler Samp & 2.7 \\
\hline & & 2.4.2 Syringe Samples & 2.7 \\
\hline & & 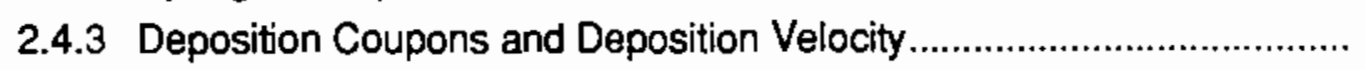 & 2.8 \\
\hline & 2.5 & 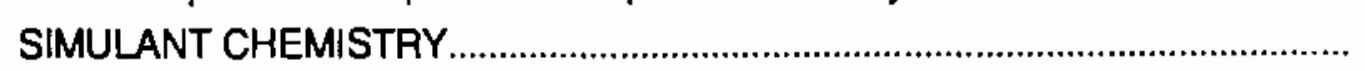 & 2.8 \\
\hline & & 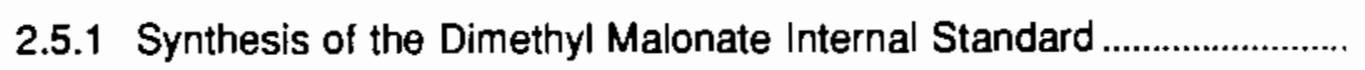 & 2.8 \\
\hline & & 2.5.2 GC/MS Separation of Dimethyl Malonate and Diethyl Malonate ........ & 2.9 \\
\hline & & 2.5.3 Quantification of Diethyi Malonate by Selected Ion Monitoring ........... & 2.10 \\
\hline & & 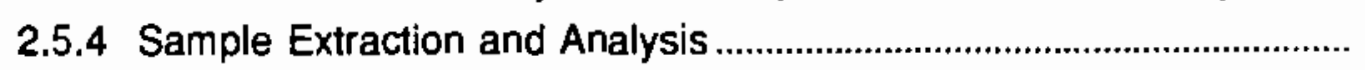 & 2.12 \\
\hline & 2.6 & ESTIMATION OF DOSE TO PLANT AND SOIL SURFACES & 2.13 \\
\hline & 2.7 & PLANT EFFECTS & 2.13 \\
\hline & & 2.7.1 Gross Phytotoxicity......... & 2.13 \\
\hline & & 2.7.2 Metabolic Effects .......... & 2.14 \\
\hline & 2.8 & SOIL MICROBIAL ASS & 2.15 \\
\hline & & 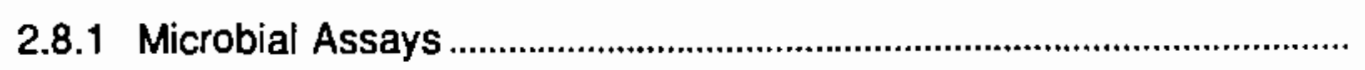 & 2.15 \\
\hline & 2.9 & SOIL INVERTEBRATE MEASUREMENTS & 2.16 \\
\hline & & & 2.17 \\
\hline 3.0 & RES & SULTS AND DISCUSSION.... & 3.1 \\
\hline & & AEROSOL CHARACTERIZAT & 3.1 \\
\hline & & 3.1.1 Aerosol Concentration ........... & 3.1 \\
\hline
\end{tabular}


3.1.2 Deposition Velocity to Surrogate Surfaces

Page

3.2 MASS LOADING ON AND DEPOSITION VELOCITIES TO FOLIAR

SURFACES AND SOILS............................................................................ 3.4

3.2.1 Vegetative Surfaces .............................................................................. 3.5

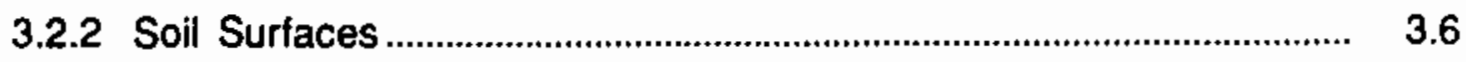

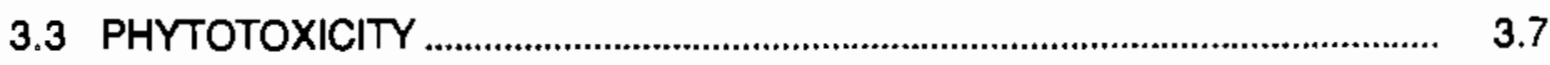

3.3.1 Gross Phytotoxicity................................................................................ 3.7

3.3.2 Metabolic Effects on Plants ............................................................... 3.10

3.4 EFFECTS ON SOIL MICROBES.................................................................. 3.10

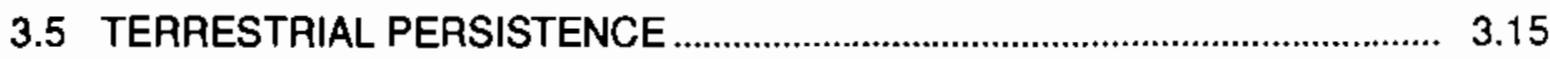

3.5.1 Persistence of DEM in Soil............................................................... 3.15

3.5.2 Persistence of DEM on Foliar Surfaces.............................................. 3.16

3.6 EFFECT OF DEM ON EARTHWORM SURVIVAL ........................................ 3.18

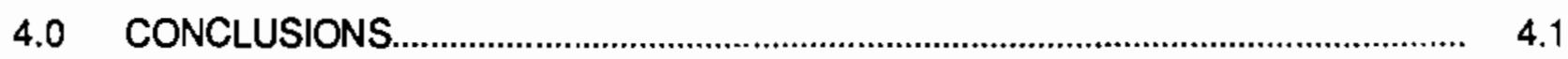

5.0 QUALITY ASSURANCE AND QUALITY CONTROL ……..................................... 5.1

5.1 QUALITY ASSURANCE

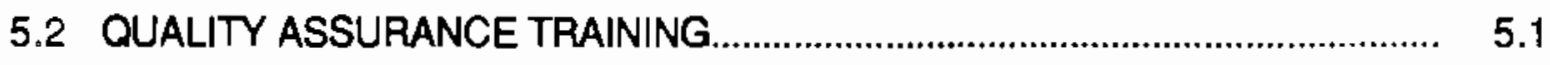

5.3 PROCEDURE REVIEW AND APPROVAL (SOP) ......................................... 5.2

5.4 LABORATORY RECORD BOOKS ............................................................ 5.2

5.5 SAMPLE IDENTIFICATION AND TRACEABILITY ........................................ 5.2

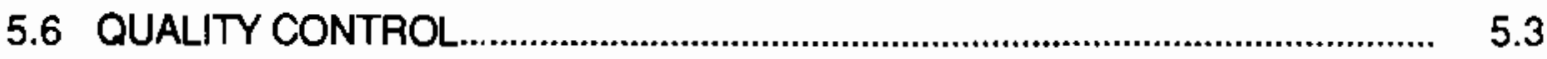

5.7 PROCEDURE QUALITY CONTROL ........................................................ 5.3

5.8 SAMPLING QUALITY CONTROL.............................................................. 5.3

5.9 ANALYTICAL QUALITY CONTROL ......................................................... 5.4

5.10 EXPERIMENTAL PROTOCOLS ………........................................................ 5.5

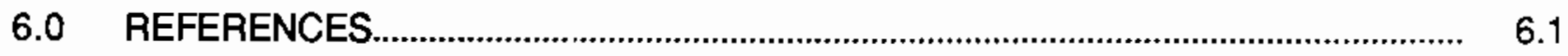


2.1. ACUTE-DOSE AEROSOL EXPOSURE CHAMBER FOR DEM TESTS …................ 2.2

2.2 TOTAL ION CURRENT CHROMATOGRAM (TOP) AND SPECTRUM (BOTTOM) OF DIETHYL MALONATE

2.3 TOTAL ION CURRENT CHROMATOGRAM (TOP) AND SPECTRUM (BOTTOM) OF SYNTHETIC DIETHYL MALONATE

2.4 STANDARD CURVE FOR DIETHYL MALONATE

2.5 TOTAL ION CURRENT CHROMATOGRAM (TOP) AND SELECTED ION CURRENT CHROMATOGRAM (BOTTOM) FOR DIETHYL MALONATE EXPOSED SHORT-NEEDLE PINE LEAVES

3.1 RESPONSE CURVE FOR THE EFFECT OF DEM ON BURBANK AND PALOUSE SOIL DEHYDROGENASE ACTIVITIES.

3.2 RESPONSE CURVE FOR THE EFFECT OF DEM ON BURBANK AND PALOUSE SOIL PHOSPHATASE ACTIVITIES

3.3 DEPURATION OF DEM IN PALOUSE SOIL ............................................................15

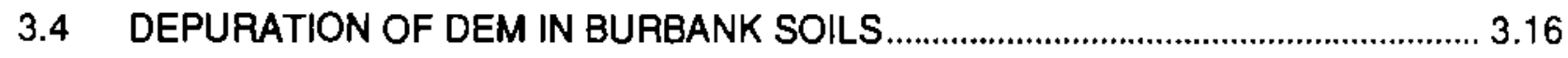

3.5 DEPURATION OF DEM DEPOSITED TO PLANT CANOPIES OF SAGEBRUSH (SB), TALL FESCUE (TF), AND SHORT-NEEDLE PINE (SNP) 


\section{LIST OF TABLES}

1.1. LIST OF CHEMICAL AGENT SIMULANTS AND DECONTAMINANTS CURRENTLY IN USE BY THE U.S. ARMY 1.2

2.1. CONDITIONS DURING DEM AEROSOL EXPOSURE TESTS. 2.4

2.2 AEROSOL GENERATION RATES FOR NEAT CHEMICAL AGENT SIMULANT AND OTHER LIQUIDS USING ANABCO NO. 535092 NEBULIZER AT 10 pSI AND STP.

2.3 AEROSOL GENERATION DURING DEM EXPOSURE TESTS 2.6

2.4 CODING FOR MODIFIED DAUBENMIRE RATING SCALE AND ASSOCIATED PHYTOTOXICITY SYMPTOMS.

2.5 SELECTED PROPERTIES OF SOILS USED IN THE DEM STUDIES 2.15

3.1 RESULTS OF BUBBLER SAMPLES OBTAINED DURING DEM AEROSOL TESTS.

3.2 RESULTS OF SYRINGE SAMPLES OBTAINED DURING DEM AEROSOL TESTS.

3.3 AVERAGE FOLIAR MASS LOADING AND DEPOSITION VELOCITIES FOR DEM ON VEGETATIVE SURFACES DURING LOW-AND HIGH-DOSE EXPERIMENTS

3.4 AVERAGE SOIL MASS LOADING (AND DEPOSITION VELOCITIES) FOR DEM ON SOIL SURFACES DURING THE LOW-AND HIGH-DOSE EXPERIMENTS

3.5 PLANT SYMPTOMOLOGY TO DEM EXPOSURE.

3.6 EFFECTS OF DEM ON THE REGROWTH (DRY-MATTER PRODUCTION) OF FOLIARLY EXPOSED TALL FESCUE PLANTS AT 30 AND 60 DAYS POSTEXPOSURE.

3.7 THE EFFECT OF DEM ON BURBANK AND PALOUSE SOIL DEHYDROGENASE ACTIVITIES

3.8 THE EFFECT OF DEM ON BURBANK AND PALOUSE SOIL PHOSPHATASE ACTIVITIES

3.9 INFLUENCE OF SOIL DEPOSITED DEM ON THE SURVIVAL OF EARTHWORMS (Eisenia foetida). 


\section{ACUTE ENVIRONMENTAL TOXICITY AND PERSISTENCE OF \\ DEM, A CHEMICAL AGENT SIMULANT: \\ DIETHYL MALONATE}

\subsection{INTRODUCTION}

Army Regulation (AR) 200-2 integrates environmental considerations into Army plans and programs. As implemented by the U.S. Army Materiel Command, this regulation requires environmental analyses and documentation for all items developed by subordinate research and development commands. CDREC as the developer is responsible for research to generate environmental data on chemical simulants. The purpose of the research effort is to determine the environmental fate and effects of simulants in terrestrial and aquatic systems. These data are used to support environmental issues on simulant use in testing, trialing, and training.

Chemical simulants are substances whose characteristics partially resemble selected physical and chemical properties of chemical agents. Simulants are used in testing or trialing to determine the performance of equipment. Simulants are aiso used in training troops to operate equipment, and to perform in a chemically contaminated environment.

The use of chemical agent simulants and decontaminants at both U.S. and foreign training sites has the potential for producing significant environmental impacts. Only limited data on the chemistry and behavior of these materiels are available (Reinbold et at. 1986, Howard et ai. 1985).

The CRDEC Environmental Fate and Eftects Data Base is a compilation of physical, chemical, toxicological and environmental data of selected simulant agents. This data base also contains available data on chemicals employed for decontamination of simulant and agent contaminated equipment. The computerized data base can be accessed through the CRDEC Data Management Office. Reinbold et al. (1986) used this data base to conduct a hazard ranking of simulants. Based on this study, simulants were identified that required laboratory data to determine their environmental persistence and acute terrestrial and aquatic toxicity. Based on the rankings on Reinbold et al. (1986) simulants were selected from those shown in Table 1.1 that required further laboratory data to determine their environmental persistence and acute terrestrial and aquatic toxicity. 


Chemical Material CAS Number

\section{Simulant Agents}

Bis (2-ethylhexyl) 2-ethylhexyl phosphonate

Bis (2-ethylhexyl) phosphonate BIS)

n-Butyl mercaptan (BUSH)

2-chloroethyl ethyl sulfide (CEES)

Diethyl adipate

Di (2-ethythexyl) phthalate (DOP)

Diethyl hydrogen phosphonate (DE:HP)

Diethyl malonate (DEM)

Diethyl phthalate (DEP)

Diethyl pimelate

Diethyl sebacate (DES)

Disopropyl fluorophosphate (DFP)

Diisopropyl methylphosphonate (DIMP)

Dimethyl adipate (DMA)

Dimethyl hygrogen phosphonate (DMHP)

Dimethyl methylphosphonate (DMMP)

Diprophylene glycol monomethyl ether (DPGME)

Ethanol

Ethyl chloroacetate (ECA)

Biethyl mercaptosuccinate, 0,0-dimethyl phosphorodithioate (Malathion)

Methyl salicylate

Diethyl p-nitrophenyl phosphate (Paraoxon)

Diethyl p-nitrophenyl thiophosphate (Parathion)

Polyethylene golycol 200 (PEG 200)

Triethyl phosphate (TEP)

Trimethyl phosphate (TMP)

Decontaminants

Diethylenetriamine

Perchloroethylene

Phenol

Chlorobenzene
126-63-6

3658-48-8

109-79-5

693-07-2

141-28-6

117-81-7

762-04-9

105-53-3

84-66-2

2050-20-6

110-40-7

55-91-4

1445-75-6

627-93-0

868-85-9

756-79-6

34590-94-8

64-17-5

105-39-5

121-75-5

119-36-8

$311-45-5$

56-38-2

25322-68-3

78-40-0

512-56-1

$111-40-0$

127-18-4

108-95-2

108-90-7 
The objective of these studies is to determine the potential acute enviromental effects and persistence of various classes of agent simulants. This report is one of a series, and it addresses just one of the chemical agent simulants listed in Table 1.1, namely diethyl malonate (DEM). Previous reports (Van Voris et al., 1987; Cataldo et al., 1988; Cataldo et al., 1989a; Calaldo et al., 1989b) described the environmental effects and chemical fate of diisopropyl methyiphos-phonate (DIMP), diisopropyl fluorophosphate (DFP), and 2-chloroethylethyl sulfide (CEES), bis (2ethylhexyl) phosphonate (BIS), and triisopropyl phosphite (TIP).

\subsection{CHEMICALPROPERTIES}

The simulant, diethyl malonate (DEM) has a viscosity and elastic shear similar to the chemical agents. Thus, it is employed in thermal decontamination studies, shipboard decontamination design, shipboard washdown, contamination transfer, and vehicle entry/exit studies. While a relatively limited data base exists on the fate and effects of DEM, the documents of Bennett et al. (1984) and Howard et al. (1985) contain pertinent information concerning the chemical characteristics, stability, and toxicity of DEM.

DEM, the chemical formula for which is $\mathrm{CH} 2\left(\mathrm{COOC}_{2} \mathrm{H} 5\right) 2$, is an aliphatic dicarboxylic ester. It is liquid at room temperature and has a water solubility of $2.7 \%$ at $20^{\circ} \mathrm{C}$. Its important physical properties include a boiling point of $199^{\circ} \mathrm{C}$, a viscosity of 1.86 centistokes at $25^{\circ} \mathrm{C}$, and a vapor pressure of $0.249 \mathrm{~mm} \mathrm{Hg}$ at $20^{\circ} \mathrm{C}$. The compound is relatively chemically stable, and is particularly prone to hydrolysis in aqueous environments to yield ethyl alcohol and malonic acid salts.

\subsection{ENVIRONMENTALFATEANDEFEECTS}

The environmental persistence of DEM is dependent on its hydrolysis half-life, which includes acid hydrolysis to ethyl alcohol and malonic acid. DEM is subject to microbial biodegradation as is malonic acid (Pinkham et al., 1978). No reliable data are available regarding the persistence or effects of DEM in the terrestrial environment.

\subsection{OBJECTIVES}

The purpose of these studies is to provide information about the environmental behavior and effects of the agent simulant, DEM. The scope of these efforts is restricted to assessment of impacts on a limited number of terrestrial organisms based on contact toxicity and the chemical persistence of the simulant in soils and on vegetative surfaces. These studies include only cursory evaluation of major decomposition products. 


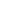




\subsection{MATERIALSAND METHODS}

The following methodology and experimental protocols were used in evaluating the environmental effects and chemical fate of DEM applied as an aerosol. Exposure tests were performed under dynamic conditions using a sealed chamber supplied with filtered air and a mixing fan to ensure uniform aerosol concentrations. Plants and soils were exposed to DEM aerosols in the chamber, and aerosols were characterized for air concentration and subsequent calculation of deposition velocities. Exposed plants and soils were sampled periodically following each test and results analyzed to provide dose and persistence information. A study of the influence of DEM on soil microorganisms was performed by amending soils with liquid DEM.

\subsection{EXPOSURESYSTEM}

Aerosol exposures of plants and soils to DEM were conducted in a sealed exposure chamber at the Pacific Northwest Laboratory (PNL) Aerosol Wind Tunnel Research Facility. The chamber and test system used were an improved version of the system used to conduct experiments with DIMP and DFP (Van Voris et al., 1987), CEES (Cataldo et al., 1988), and BIS (Cataldo et al., 1989a). Improvements to the test system prior to the DEM tests included doubling the output capacity of aerosol generation, addition of four new aerosol sampling ports, resealing all ports and windows, and reconfiguring the exhaust scrubber and filters.

The exposure chamber, shown in Figure 2.1, was used to contain the aerosol exposures. The exposure region of the chamber was $0.40 \mathrm{~m}^{2}$ with a height of 0.6 to $0.9 \mathrm{~m}$. Chamber volume was $0.37 \mathrm{~m}^{3}$. A small electric mixing fan was mounted above the grated floor to provide slow horizontal mixing within the chamber. Mixing velocities were estimated from observations of plant leaf movement to be less than $1 \mathrm{~m} / \mathrm{sec}$. Lighting to promote plant respiration during tests was provided by an incandescent lamp mounted at the back window of the chamber.

The exposure chamber was operated at a negative air pressure of $1 \mathrm{~cm}-\mathrm{H}_{2} \mathrm{O}$ during test and purge periods to contain the DEM aerosols. HEPA-filtered air was supplied to the chamber at a flow rate of about $70 \mathrm{Lpm}$. The air was first passed through the aerosol generation chamber located on the side of the chamber (Figure 2.1), to serve as a flow for DEM aerosol, and then introduced to the chamber below the level of the metal grating floor panel. Exhaust was drawn from the top of the chamber, passed through a dual-stage liquid scrubber, filters, a flowmeter, and to the facility's exhaust system. In addition to the carrier air flow, about $14 \mathrm{Lpm}$ was introduced at the aerosol generator. The leak rate of the chamber was determined from vacuum tests to be $0.04 \pm 0.02 \mathrm{Lpm}$. 


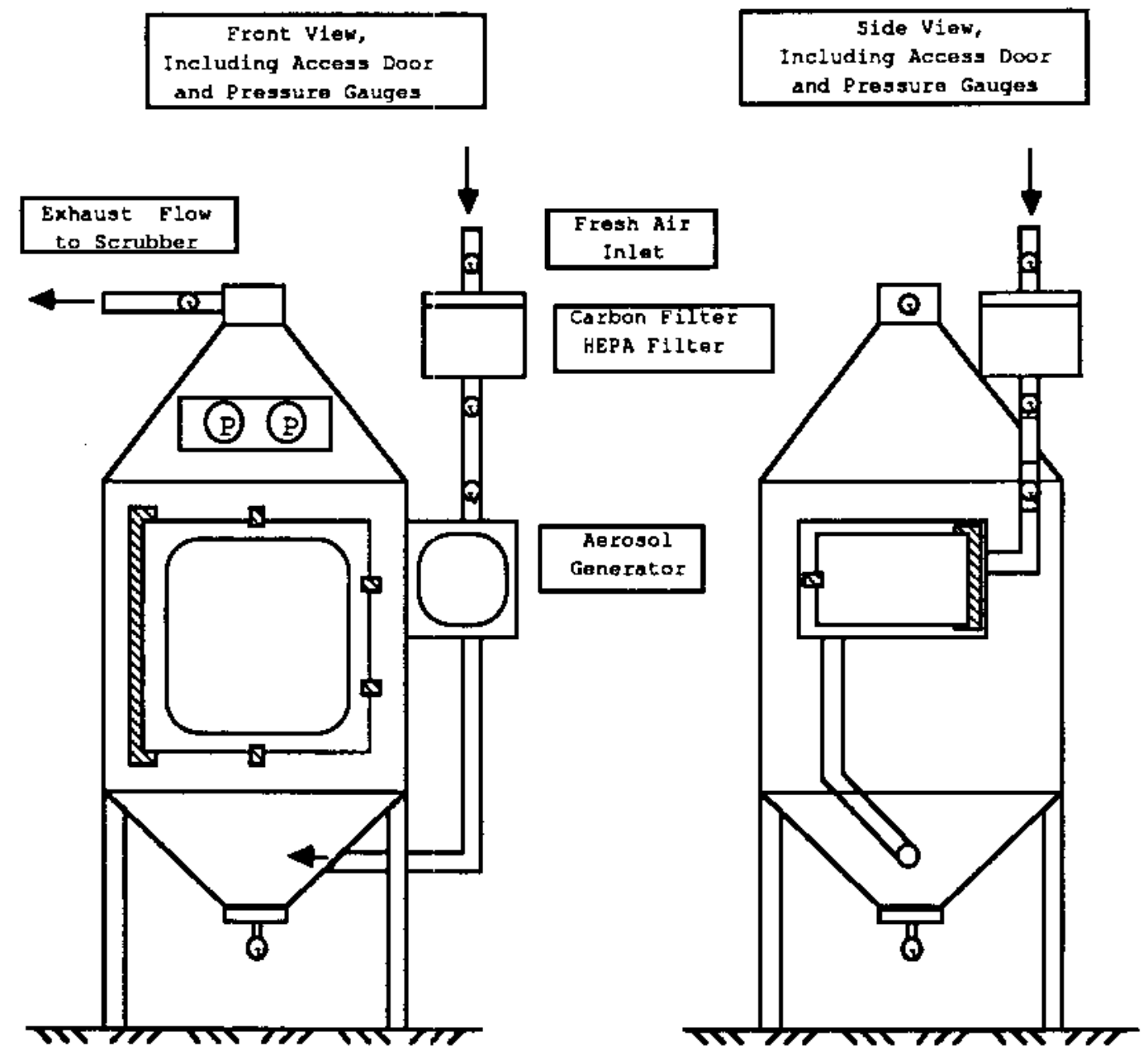

EIGURE 21. ACUTE-DOSE AEROSOL EXPOSURE CHAMBER FOR DEM TESTS 


\subsection{EXPOSURE PROTOCOL}

Three tests of DEM aerosols were performed (DEM-01, -02 , and -03 ). DEM-01 was performed as a trial test, and tests DEM-02 and -03 were actual plant and soil exposure tests. Plants, soils, and deposition coupons (47 mm glass fiber filter substrate) were placed into the test section prior to each test. At least one-half of the metal grating floor, itself with a porosity of $\sim 90 \%$, was left uncovered to ensure good aerosol mixing within the chamber. Deposition coupons were suspended horizontally within the plant canopy. Rubber access doors on both the exposure and generation chambers were sealed before each test using clamps. Sealant grease was not required because of the very low leak rate at $-1 \mathrm{~cm}-\mathrm{H}^{2} \mathrm{O}$. The lamp and mixing fan were turned on and the carrier air flow established. Aerosols were generated by applying compressed air to nebulizers. Tests were $60 \mathrm{~min}$ in duration, followed by purge periods of $10 \mathrm{~min}$ to allow the chamber to clear of aerosol.

Generation of DEM aerosol was tested during the trial test and rates were adjusted to provide concentrations during the subsequent plant and soil exposures equal to the target concentrations of 150 and $1500 \mathrm{mg} / \mathrm{m}^{3}$. Samples of the aerosol were obtained during the tests using both gas sampling syringes (grab samples) and bubblers to trap DEM present in known volumes of the chamber atmosphere. From these samples, air concentrations of DEM aerosols were determined.

Immediately following the purge period, plants and soils were removed from the chamber and the first samples were obtained. After sampling, plants were placed in a growth chamber for subsequent sampling and observation. Deposition coupons were also removed from the chamber and placed into vials of methylene chloride.

The exposure system was decontaminated after tests DEM-01 and DEM-03 by contacting all surfaces with copious amounts of $0.5 \mathrm{~N} \mathrm{NaOH}$. The system was then rinsed with with water and allowed to dry prior to subsequent tests. Components of the aerosol generation system were also decontaminated and cleaned. No chamber cleaning was performed between the low and high dose tests DEM-02 and DEM-03 because the tests were performed sequentially on the same day and residual contamination from the low dose test were determined to be of no significance to the high dose test.

Test conditions are listed in Table 2.1. Temperature and relative humidity were measured at the inlet to the chamber. 
IABLE2.1. CONDITIONS DURING DEM AEROSOL EXPOSURE TESTS

\begin{tabular}{lccccccc}
\hline Test & Date & $\begin{array}{c}\text { Temperature } \\
\left({ }^{\circ} \mathrm{C}\right)\end{array}$ & $\begin{array}{c}\text { Relative } \\
\text { Humidity } \\
(\%)\end{array}$ & $\begin{array}{c}\text { Duration } \\
\text { Test Purge } \\
(\mathrm{min})\end{array}$ & $\begin{array}{c}\text { Flow } \\
(\mathrm{min})\end{array}$ & $\begin{array}{c}\text { Rest } \\
(\text { Lpm })\end{array}$ & $\begin{array}{c}\text { Rate } \\
\text { Purge } \\
(\mathrm{Lpm})\end{array}$ \\
\hline DEM-01 & $9 / 26 / 89$ & 21 & 48 & 60 & 10 & 74 & 69 \\
DEM-02 & $9 / 28 / 89$ & 24 & 35 & 60 & 10 & 84 & 65 \\
DEM-03 & $9 / 28 / 89$ & 25 & 35 & 60 & 10 & 85 & 83 \\
\hline
\end{tabular}

Flow rates in the system during the tests were determined as the sum of all flows using a vane anemometer to measure the inlet carrier air flow and a flowmeter for the compressed air used in the aerosol generator. The small leak rate $(0.04 \mathrm{Lpm})$ did not significantly influence air flow in the test system.

\subsection{AEROSOL GENERATION}

DEM aerosols were generated intermittently or continuously during tests using one or two $A B C O$ No. 535092 polyethylene nebulizers. Neat DEM was poured into the $25-\mathrm{mL}$ reservoir of the nebulizers. The nebulizers were placed into the aerosol generation chamber and monitored through a window during all tests. A single nebulizer was operated continuously using $10 \mathrm{psi}$ filtered compressed air during trial test DEM-01. Results of that test indicated the need to increase aerosol generation rates at least two times; therefore, a second nebulizer was added and connected in parallel to the first nebulizer. Air pressure was also increased to $15 \mathrm{psi}$ to increase the rate of aerosol generation.

Nebulizers were selected to generate DEM aerosols for the current study because they provided easily controllable steady generation rates of undiluted DEM droplets in the micrometer size range. The generation process could be started or stopped within less than $0.5 \mathrm{sec}$ and remained unaffected by repeated intermittent periods of use. In the nebulizers, aerosols of DEM were produced by aspirating liquid from the reservoirs by the suction force supplied by the expanding compressed air jets. The liquid was then spread as a thin film around a spherical obstruction in the air jet, atomized by shear forces at the edges of the sphere, and dispersed in the turbulent flow downstream of the sphere. Only small droplets were produced, large droplets were impinged on the outlet tube of the nebulizers and drained back into the reservoirs. Because the liquids were composed of neat DEM, no fractional evaporation and solution concentration 
occurred because of this refilling process, and the generation process efficiently produced only air-suspended droplets and vapor. Other generation methods that were considered included spray atomization and vaporization/condensation; however, no other method provided sufficient control over chemical purity or aerosol concentration.

Because the rate of aerosol generation from nebulizers is dependent on liquid properties such as viscosity, as well as the specific nebulizer geometry, the rate of generation for DEM was determined in trial test DEM-01. During that test, generation of DEM was continuous and $10 \mathrm{psi}$ compressed air was supplied to the system to provide similar conditions to those used previously for other agent simulants. Because DEM was the fifth simulant generated for exposure tests, a comparison of generation rates from the same nebulizer for several chemicals was made, and is shown in Table 2.2. Rate of generation is seen to increase with decreasing molecular weight (and decreasing vapor pressure). Exceptions to this include $\mathrm{H}_{2} \mathrm{O}$, possibly because of its strong polarity, and DEM, for unknown reasons. Because of slight differences between the two nebulizers used in the DEM tests, rates of generation from the second nebulizer were seen to be 1.3 to 1.8 times greater than those from the first nebulizer (the one used in all previous tests); the range of differences between the two nebulizer generation rates was attributed to different liquid properties of the various tested materials.

TABLE 2.2. AEROSOL GENERATION RATES FOR NEAT CHEMICAL AGENT SIMULANTS AND OTHER LIQUIDS USING ANABCO NO. 535092 NEBULIZER AT 10 psi AND STP

\begin{tabular}{lccccc}
\hline Chemical & $\begin{array}{l}\text { Molecular } \\
\text { Weight }\end{array}$ & $\begin{array}{c}\text { Viscosity } \\
\text { (centistokes) }\end{array}$ & $\begin{array}{c}\text { Vapor Pressure } \\
(\mathrm{mm}-\mathrm{Hg})\end{array}$ & $\begin{array}{c}\text { Density } \\
(\mathrm{g} / \mathrm{mL})\end{array}$ & $\begin{array}{c}\text { Rate of } \\
\text { Generation } \\
(\mathrm{mL} / \mathrm{min})\end{array}$ \\
\hline BIS & $\sim 308$ & 6.6 & 0.000058 & 0.94 & $0.19 \pm 0.01$ \\
DIMP & 180 & & 0.17 & 0.98 & $\sim 0.3$ \\
DEM & 160 & & 0.25 & 1.055 & 0.19 \\
DFP & 184 & & 0.58 & 1.055 & $\sim 0.4$ \\
CEES & 125 & & 3.4 & 1.070 & $0.40 \pm 0.03$ \\
H2O & 18 & & 17.5 & 1.000 & $0.11 \pm 0.02$ \\
Ethanol & 46 & & $\sim 45$ & 0.79 & $0.52 \pm 0.03$ \\
Methanol & 32 & & -100 & 0.79 & $0.56 \pm 0.02$ \\
\hline
\end{tabular}


Rates of DEM aerosol generation during the current exposure tests are shown in Table 2.3. Again, the rate during trial test DEM-01 was less than that during the subsequent tests because only one nebulizer was used and because it was operated at a compressed air pressure of $10 \mathrm{psi}$ rather than $15 \mathrm{psi}$. No accumulation of droplets or other deposits occurred in the aerosol generation chamber during the tests, indicating aerosol generation efficiency was not influenced by generation rate. An interesting difference between the aerosol generated during the low dose and those generated during the high dose tests was noted; during the low dose test a droplet aerosol was visible in the generation chamber, but not in the exposure chamber, however, during the highest dose test (DEM-03), a dense DEM-droplet aerosol was visible in both locations. Accordingly, a light haze was observed in the exposure chamber during the first high dose test (DEM-01) when aerosol was generated at an average rate 3.5 times greater than DEM-02, and 3.2 times less than DEM-03.

IABLE2.3. AEROSOL GENERATION DURING DEM EXPOSURE TESTS. A single operated at 15 psi during DEM-02 and DEM-03. Test durations were $60 \mathrm{~min}$.

\begin{tabular}{|c|c|c|c|c|c|}
\hline Test & Dose & $\begin{array}{c}\text { Generation } \\
\text { Period }\end{array}$ & $\begin{array}{c}\text { No. of } \\
\text { Nebulizers }\end{array}$ & $\begin{array}{c}\text { Generation } \\
\text { Rate } \\
\text { (g/min) }\end{array}$ & $\begin{array}{c}\text { Test-Average } \\
\text { Generation Rate } \\
\text { (g/min) }\end{array}$ \\
\hline DEM-01 & Trial/High & Continuous & 1 & 0.18 & 0.18 \\
\hline DEM-02 & Low & Intermittent(a) & 2 & 0.50 & $0.052^{(b)}$ \\
\hline DEM-03 & High & Continuous & 2 & 0.57 & 0.5 \\
\hline
\end{tabular}

(a) Intermittent generation consisted of 12 periods $30 \mathrm{sec}$ of generation followed by $270 \mathrm{sec}$ of non-generation.

(b) Test average generation rate obtained by mukiphying the instantaneous generation rate by the ratio of time on to time oft.

\subsection{AEROSOL CHARACTERIZATION}

Procedures for DEM aerosol generation were determined for initial target concentrations of 100 and $1000 \mathrm{mg} / \mathrm{m}^{3}$. Because it was not clear that it would be possible to obtain adequate amounts of DEM for analysis from plant and soil samples, especially after hours and days of depuration, results of trial test DEM-01 (aerosol concentration $\sim 500 \mathrm{mg} / \mathrm{m}^{3}$ ) were used to provide aerosol generation methods for slightly increased target DEM air concentrations of 150 and 1500 $\mathrm{mg} / \mathrm{m}^{3}$. (A small mass of DEM evaporated within 8 to $16 \mathrm{~h}$ at STP). Measurements were 
performed to characterize the concentration of DEM aerosol in the exposure chamber during the tests using bubbler, syringe, and deposition coupons samples.

\subsubsection{Bubbler Samples}

Two Ace Glass Co. No. 7529 smog bubblers were used to obtain time-averaged samples of DEM aerosol mass concentration during all tests. The bubblers were operated with methylene chloride solvent to trap DEM. Sampling periods were 10 to $20 \mathrm{~min}$ in duration, and bubblers were used twice during the trial test, four times during DEM-02, and five times during DEM-03. In addition, one pre-test bubbler sample was obtained prior to DEM-02 to provide a control for analysis. The bubblers were operated in series during trial test DEM-01 to test for DEM carry through. After carrythrough was shown to be limited to less than $4 \%$ (DEM in the second bubblers was less than the detectable limit, 25 times the detectable limit was collected in the leading bubblers), single bubblers were operated during the subsequent tests.

Flow rates and sample durations were monitored and recorded during each sample. Flow rate was controlled at about $0.3 \mathrm{Lpm}$ and monitored using a Singer Instrument Co. Dry Test Meter Model 115. Post-test sample volumes were removed from the bubblers using pipets to avoid contact with the halocarbon grease at the top seal of the bubblers. The sample volumes were then measured and recorded. Subsequent analysis for DEM was determined as concentration of DEM in the sample liquid. Determination of aerosol mass concentration in the exposure chamber was then calculated by multiplying the concentration of DEM in the bubbler liquid by total volume of chamber atmosphere sampled.

\subsubsection{Syringe Samples}

Four grab samples were also obtained during each exposure test (DEM-02 and DEM-03). Samples were obtained by drawing $60 \mathrm{~mL}$ of exposure chamber atmosphere into a 100-mL gas sampling syringe constructed of glass and Teflon. Samples were drawn at recorded periods through a $10-\mathrm{cm}$ large-bore stainless steel needle. About $10 \mathrm{~mL}$ of methylene chloride were then drawn through the needle into the syringe, and the mixture of aerosol and solvent were contacted by shaking and swirling the syringe for about $2 \mathrm{~min}$. The resulting solution was then replaced into the original sample vial. The syringe was cleaned by rinsing with clean solvent between sampling periods.

Two samples collected during DEM-03 were rinsed three times each and all solutions analyzed to determine the efficiency of removal of sampled DEM from the syringe. Residual in the second rinse was $3 \pm 2 \%$ of the mass sampled. Residual DEM in the third rinse was not 
detectable, indicating that less than $0.1 \%$ of the DEM was not removed after two rinses. Data obtained was increased by $3 \%$ (as, unlike the bubblers, an absolute carrythrough value was determined), multiplied by the ratio of the solvent volume analyzed to that collected to determine the total mass of DEM collected, and then multiplied by the gas sample volume to determine aerosol mass concentration in the exposure chamber.

\subsubsection{Deposition Coupons and Deposition Velocity}

Four deposition coupons were placed in the exposure chamber within the plant canopy during tesls DEM-02 and DEM-03. The 47-mm glass fiber deposition coupons (Gelman Type AV) were suspended horizontally on spring holders. The total area available for deposition, including both top and bottom but not the area covered by the spring holder, was $34.0 \mathrm{~cm}^{2}$. Deposition coupons were collected after the purge period and placed into vials containing $10 \mathrm{~mL}$ of methylene chloride.

Results of the deposition coupon samples were used to obtain the deposition velocity of DEM to a surrogate surface for comparison with rates determined for plant and soil samples. The total mass of DEM on each coupon was divided by the product of the chamber concentration, coupon area, and test duration to determine deposition velocity.

\subsection{SIMULANT CHEMISTRY}

\subsubsection{Synthesis of the Dimethyl Malonate Internal Standard}

Dimethyl malonate was chosen as an internal standard because of its obvious chemical similarity to diethyl malonate as well as its anticipated similar but slightly lower retention time on the polar analytical column. Dimethyl malonate was synthesized from malonic acid by standard esterification procedures. Briefly, synthesis involved mixing $200 \mathrm{~mL}$ methanol, $150 \mathrm{~mL}$ toluene, 4 drops of concentrated sulfuric acid and $2.00 \mathrm{~g}$ malonic acid $(0.0192$ moles $)$ in a $500-\mathrm{mL}$ roundbottomed flask. The solution was stirred by means of a magnetic stir bar under reflux conditions overnight at which time the methanol was stripped from the reaction mixture by means of a rotary evaporation apparatus. The remaining toluene solution was washed two times with $100-\mathrm{mL}$ portions of $5 \%$ aqueous $\mathrm{NaHCO}_{3}$ followed by a wash with $100 \mathrm{~mL}$ of saturated aqueous $\mathrm{NaCl}$. The toluene layer was dried by the addition of anhydrous $\mathrm{Na}_{2} \mathrm{SO}_{4}$. After removal of the $\mathrm{Na}_{2} \mathrm{SO}_{4}$ by filtration, the toluene was evaporated under reduced pressure. The remaining dimethyl malonate product was a colorless oil whose identity was later confirmed by GC/MS studies. 


\subsubsection{GC/MS Separation of Dimethyl Malonate and Diethyl Malonate}

All analyses were performed on a Hewlett-Packard Model 5890A gas chromatograph interfaced to a Hewlett-Packard Model 5970A mass spectrometer. Separations were conducted on a $30 \mathrm{~m} \times 0.255 \mathrm{~mm}$ i.d. DB-Wax fused silica column ( $\mathrm{J}$ \& W Scientific, Folsom, CA). The column contained a $0.25-\mu \mathrm{m}$ polar film of crosslinked carbowax stationary phase. Samples were introduced to the column through 1.0- $\mu \mathrm{L}$ splitless injections. After an initial hold at $40^{\circ} \mathrm{C}$ for 2 min, the column was temperature programmed from 40 to $220^{\circ} \mathrm{C}$ at a rate of $6{ }^{\circ} \mathrm{C} / \mathrm{min}$. During chromatographic runs, nominal resolution mass spectra were collected by ramping the quadrupole mass spectrometer from 40 to $600 \mathrm{amu}$ at a rate of $200 \mathrm{amu} / \mathrm{sec}$.

A total ion current chromatogram for an injection of diethyl malonate (Aldrich Chemical Co., Milwaukee, WI) is presented in the top of Figure 2.2. The retention time of 14.5 min was observed for this compound under the chromatographic conditions employed. The $70-\mathrm{eV}$ mass spectrum of diethyl malonate is shown in the bottom of Figure 2.2. This spectrum contains a predominant fragment $(m / e=115)$ arising from the loss of ethoxy from the parent compound.

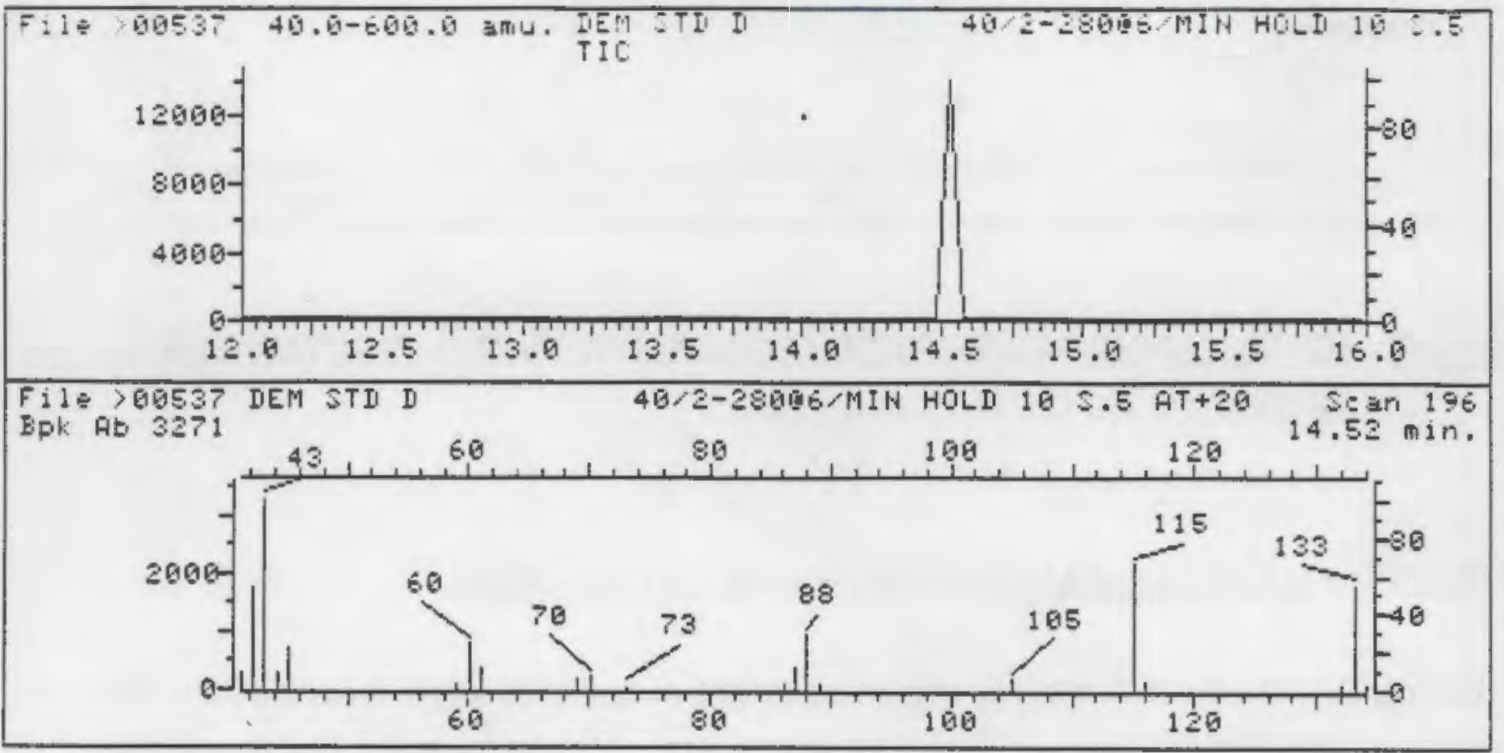

\section{EIGURE22. TOTAL ION CURRENT CHROMATOGRAM (TOP) AND SPECTRUM (BOTTOM)} OF DIETHYL MALONATE 
The total ion current chromatogram of synthetic dimethyl malonate gave a single peak. This chromatogram is shown in the top of Figure 2.3 with the resulting mass spectrum presented in the bottom of the Figure 2.3. The retention time of dimethyl malonate $(13.0 \mathrm{~min})$ was sufficiently different from diethyl malonate to allow use of dimethyl malonate as an internal standard. The mass spectrum obtained from the synthetic dimethyl malonate matches literature spectra (Heller and Milne, 1978), thus assuring synthesis of the correct compound. The spectra of dimethyl malonate shows a predominant loss of methoxy from the parent compound giving rise to the fragment at $\mathrm{m} / \mathrm{e}$ of 101 .

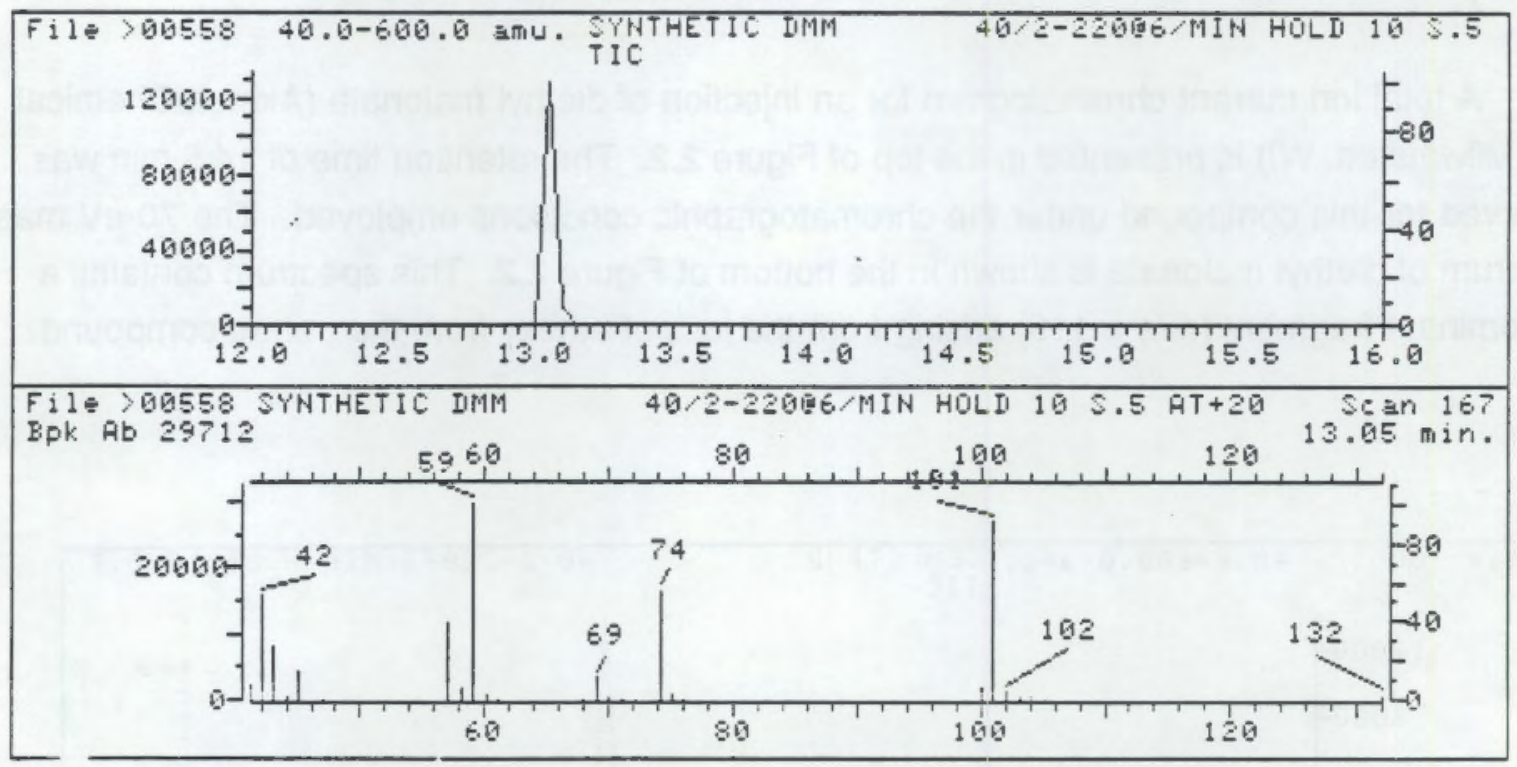

\section{EIGURE2.3. TOTAL ION CURRENT CHROMATOGRAM (TOP) AND SPECTRUM (BOTTOM) OF SYNTHETIC DIETHYL MALONATE}

\subsubsection{Quantification of Diethyl Malonate by Selected lon Monitoring}

During the course of this study organic extracts of samples were examined for the concentration of diethyl malonate. Extracts from several of these samples (most notably sagebrush and short-needle pine leaf tissues) were expected to contain high concentrations of indigenous oils (mostly terpenes and sesquiterpenes). Due to the difficulties in attempting to accurately quantitate diethyl malonate in these highly complex extracts, selected ion monitoring was utilized to increase the selectivity of the analysis. The ions which were monitored were $\mathrm{m} / \mathrm{e}$ of 115 (specific for diethyl malonate) and $\mathrm{m} / \mathrm{e}$ of 101 (specific for the dimethyl malonate internal 
standard). The dwell time utilized was $100 \mathrm{~m} / \mathrm{sec}$ at an electron multiplier voltage of 200 volts above the perfluorotributylamine tune voltage ( 2000 volts). The sampling rate was in excess of the minimum criterion set forth by Matthews and Hayes (1976) for accurate integration of chromatographic peaks during selected ion acquisition. The chromatographic separation conditions remained identical to those previously described. An additional advantage of selected ion monitoring was an increase in sensitivity over the scanning mode. The increase in sensitivity was especially important when monitoring time-course samples since the concentration of analyte contained in the extracts became increasingly diminished.

A standard curve for diethyl malonate was prepared as described below. A concentrated stock solution of dimethyl malonate was prepared in methylene chloride ( $500 \mu \mathrm{L}$ dimethyl malonate/25.0 mL methylene chloride). A series of diethyl malonate standards, ranging in concentration from 10 to $110 \mathrm{ppm}$, were prepared in methylene chloride. A $10.0-\mathrm{mL}$ aliquot of each standard was spiked with $25.0 \mu \mathrm{L}$ of the internal standard stock solution. The standard solutions were run under the selected ion monitoring conditions described above. By plotting the ratio of the diethyl malonate integrated peak area to that of the internal standard as a function of diethyl malonate concentration, a standard calibration curve was obtained. The standard curve is presented in Figure 2.4. The detection limit of diethyl malonate under the selected ion monitoring conditions was approximately $125 \mathrm{pg} / \mathrm{injection.}$

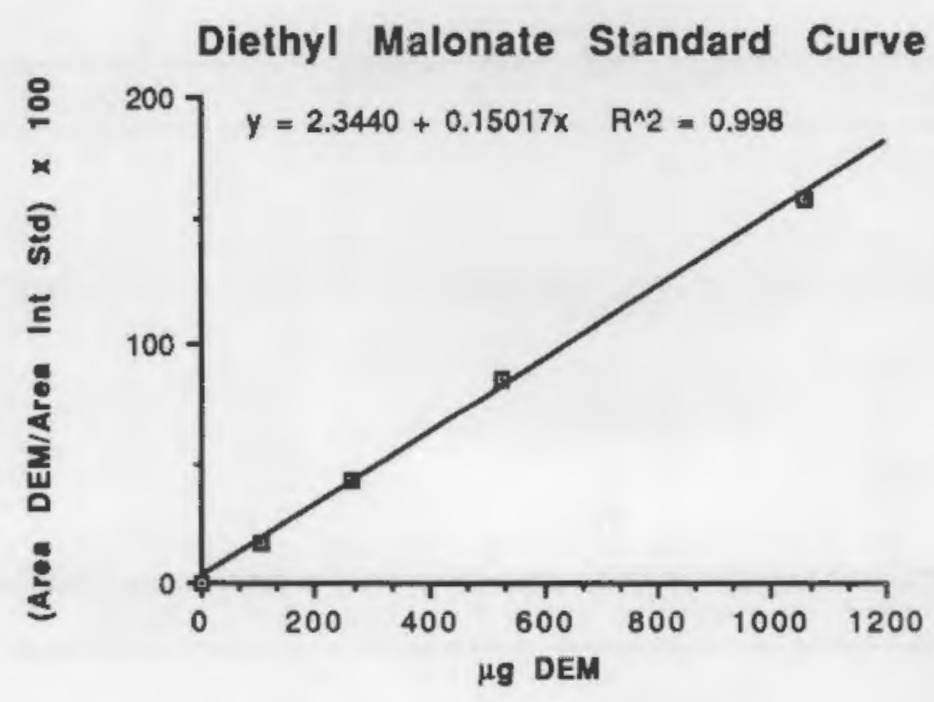

EIGURE 2.4. STANDARD CURVE FOR DIETHYL MALONATE 


\subsubsection{Sample Extraction and Analysis}

All samples generated during this study were immediately extracted into approximately 10 $\mathrm{mL}$ of methylene chloride. Sample vials were sealed with Teflon lined caps to prevent evaporation and immediately transported to the chemical analysis laboratory. Each sample was promptly spiked with $25.0 \mu \mathrm{L}$ of internal standard stock solution, thoroughly mixed, transferred to crimp-top autosampler vials, and expediently analyzed. Comparison of the diethyl malonate/dimethyl malonate peak areas in each sample to the calibration curve shown in Figure 2.4 formed the basis for quantification throughout the analysis.

An example of the increased selectivity afforded by selective ion monitoring over the normal scanning acquisition is presented in Figure 2.5. The total ion current chromatogram of an extract of diethyl malonate exposed short-needle pine, prior to the addition of the internal standard is shown in the top of Figure 2.5. The peak at $14.5 \mathrm{~min}$ is due to diethyl malonate.
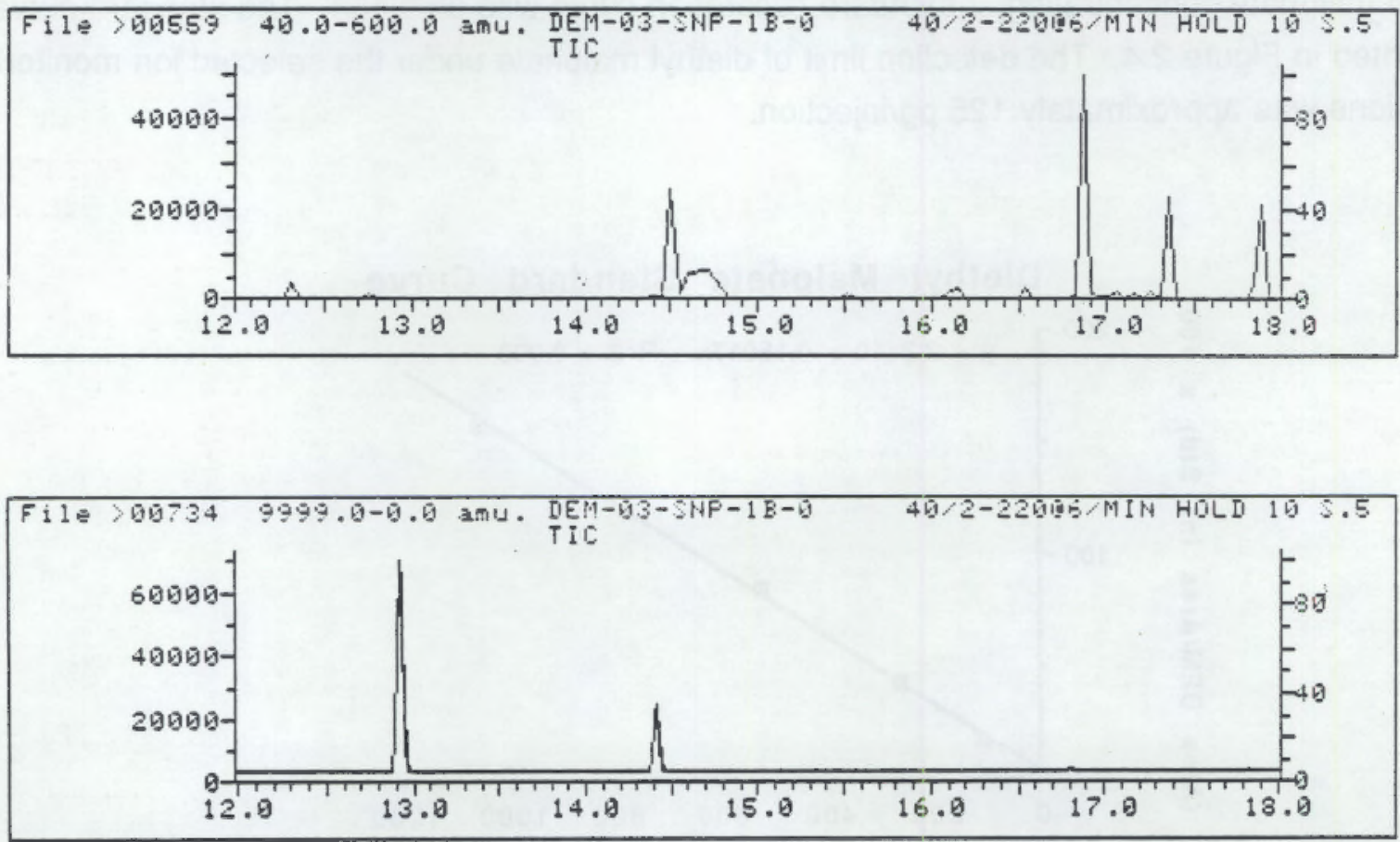

EIGURE2 2.5. TOTAL ION CURRENT CHROMATOGRAM (TOP) AND SELECTED ION CURRENT CHROMATOGRAM (BOTTOM) FOR DIETHYL MALONATE EXPOSED SHORT-NEEDLE PINE LEAVES 
The remaining peaks are due to terpenes and sesquiterpenes which were co-extracted from the pine needles. It is clear that large quantities of these natural oils could lead to severe interference in the accurate determination of diethyl malonate. The bottom of Figure 2.5 shows the chromatographic profile of the same short-needle pine extract after the addition of internal standard and under the selected ion monitoring acquisition parameters utilized by this study. The marked increase in selectivity is apparent as only two chromatographic peaks, due to the internal standard (retention time of $12.9 \mathrm{~min}$ ) and diethyl malonate, are present. This enhanced selectivity allows for far greater accuracy in quantification of diethyl malonate.

\subsection{ESTIMATION OF DOSE TO PLANT AND SOIL SURFACES}

Leaf tissue (duplicate samples from different places within the canopy) contaminated with DEM were placed in glass vials containing $10 \mathrm{~mL}$ of high-purity, distilled-in-glass methylene chloride, and extracted for $10 \mathrm{~min}$. The vials were fitted with Teflon-lined screw caps. Following extraction, the tissues were removed from the vials and leaf areas were measured using a Licor LI-3000 leaf area meter. The foliar mass loading was calculated as $\mathrm{ng}$ contaminant/ $\mathrm{cm}^{2}$ leaf surface.

Three subsamples of each soil sample were removed from Petri dishes exposed to aerosols using a cork borer (sample area was $3 \times 0.95 \mathrm{~cm}^{2}$ ), and the samples were placed into a 25- $\mathrm{mL}$ tared Corex centrifuge tube with a Teflon-lined screw cap. Five $\mathrm{mL}$ of methylene chloride were added to the soil sample, and the tube was vigorously shaken for $1 \mathrm{~min}$ before the solid and liquid phases were separated. Soil samples were centrifuged at $8000 \mathrm{xg}$ for $10 \mathrm{~min}$ at $25^{\circ} \mathrm{C}$, using a Beckman model J2-21M centrifuge. The solvent was transferred to a clean vial, and the soil samples were air dried for $16 \mathrm{~h}$ and dried at $60^{\circ} \mathrm{C}$ for $8 \mathrm{~h}$. Tared tubes were reweighed to obtain the dry weight of the soil and mass loading was calculated (ng contaminant/g soil). All sample extracts from the tests were kept frozen at $-80^{\circ} \mathrm{C}$ before analysis.

\subsection{PLANT EFFECTS}

The effects of diethyl malonate on vegetation were explored by studying evidence of phytotoxicity and metabolic effects in three species: the short-needle pine (Pinus echinata), tall fescue (Festuca arundinacea, 'K-13') and sagebrush (Artemisia tridentata, vaseyana).

\subsubsection{Gross Phytotoxicity}

Assessments of phytotoxicity resulting from foliar contamination with DEM were based on the development of visual toxicity symptoms. These symptoms included leaf burn, blade die- 
back, necrotic spotting, and chlorosis (Table 2.4). Quantitation of these effects is based on a Modified Daubenmire Rating Scale (MDRS) (Daubenmire, 1959), a discussion of which is included in the results section of this report.

\subsubsection{Metabolic Effects}

The basis of the observed whole plants phytotoxicity of DEM was further investigated using two in vitro systems: 1) the effects of the simulant on photosynthesis (oxygen evolution) and dark respiration (oxygen uptake) in intact leaf segments; and 2) the effects of the simulant on specific photochemical reactions and electron transport chains in isolated chloroplasts. Methods were described previously (Cataldo et al., 1988)

IABLE2 24. CODING FOR MODIFIED DAUBENMIRE RATING SCALE AND ASSOCIATED PHYTOTOXICITY SYMPTOMS

Symptom/Intensity

Modified Daubenmire Rating Scale

0
1
3
3
5

Phenotypic Responses

OGA

NGA

O\&NGA

TB

LBD

NS

LD

$\mathrm{Chl}$

BD

LC

W

GD

D

F/SA

(value)
Description

no obvious effects over controls

$5 \%$ of plant foliage affected

between $5 \%-25 \%$ of foliage affected

between $25 \%-50 \%$ of foliage affected

between $50 \%-75 \%$ of foliage affected

between $75 \%-95 \%$ of foliage affected

between $95 \%-100 \%$ of foliage affected

old growth affected

new growth affected

old and new growth affected

tip or leaf edge bum

leaf burn and leat drop

necrotic spolting

leaf abscission or needle drop

chlorosis

blade dieback

leaf curl

witting

growing tip dieback

plant dead

floral or seed/fruit abortion

indicates the length in $\mathrm{cm}$ that needles

op leaves exhibit dieback or burn 


\subsection{SOIL MICROBIALASSAYS}

\subsubsection{Microbial Assays}

Two soils were used to evaluate the microbiological effect of the agent simulant, diethyl malonate (DEM). They were Burbank (sandy, skeletal, mixed, xeric, Torriorthent), a sandy loam soil found at the Hanford area of Washington, and Palouse (fine-silty, mixed, mesic, Pachic Ultic Haploxerolls), a silt loam soil typical of eastern Washington agricultural areas. Selected physical and chemical properties for these two soils are listed in Table 2.5. Soils were amended with DEM (Aldrich Cat. No. D9775-4, Lot No. 03403MV, $99 \%$ pure) to final concentrations ranging from 0 to $2500 \mu \mathrm{g} \mathrm{g}^{-1}$ dry soil. Soil moisture was adjusted to $26 \%$ and $23 \%$ for the Palouse and Burbank soil, respectively. Amended soil was then incubated at $22^{\circ} \mathrm{C}$ in the dark. The effect of DEM on soil microbial activities was then evaluated in vitro by measuring the activity of the two soil enzymes, soil dehydrogenase and soil acid phosphatase.

\section{IABLE 2.5. SELECTED PROPERTIES OF SOILS USED IN THE DEM STUDIES}

\begin{tabular}{lcc}
\hline Soil Property & Burbank Sandy Loam & Palouse Silt Loam \\
\hline$\%$ Sand & 45.1 & 1.1 \\
$\%$ Silt & 51.4 & 77.5 \\
$\%$ Clay & 4.0 & 21.4 \\
$\%$ Ash & 98.0 & 93.8 \\
pH (100\% field capacity) & 7.4 & 5.4 \\
Organic carbon $(\%)$ & 0.5 & 1.7 \\
Sulfur $(\%)$ & 0.053 & 0.043 \\
Nitrogen $(\%)$ & 0.061 & 0.16 \\
Total P $(\mu \mathrm{g} / \mathrm{g})$ & 2400 & 3770 \\
Phosphate-P $(\mu \mathrm{g} / \mathrm{g})$ & 4.8 & 5.8 \\
Carbonate/Bicarbonate $(\%)$ & $<0.1$ & $<0.1$ \\
Ammonium-N $(\mu \mathrm{g} / \mathrm{g})$ & 6.1 & 18.3 \\
CEC (meq/100 g) & 5.5 & 23.8 \\
& & \\
\hline
\end{tabular}


At 3 and 28 days after the DEM amendment, soil samples were assayed for dehydrogenase activity by a modification of the method of Tabatabai (1982). An aliquot of soil ( $2.0 \mathrm{~g}$ wet weight) was first mixed with $0.3 \mathrm{~mL}$ of $\mathrm{CaCO}_{3}(3 \%, w / v), 0.15 \mathrm{~mL}$ of glucose $(3 \%, w / v)$, and $0.375 \mathrm{~mL}$ of the substrate, 2,3,5-triphenyltetrazolium chloride $(3 \% \mathrm{w} / \mathrm{v})$. After incubation at $22^{\circ} \mathrm{C}$ for $24 \mathrm{~h}, 10 \mathrm{~mL}$ of methanol was added to the soil to extract the product, $2,3,5-$

triphenylformazan (TPF). The solution was mixed thoroughly, centrifuged, and the absorbance of the supernatant determined at $485 \mathrm{~nm}$. Soil dehydrogenase activity, expressed as $\mu \mathrm{g}$ of TPF produced per gram of dry soil per $24 \mathrm{~h}$, was determined by comparing absorbance values to a standard curve prepared with reagent grade TPF and methanol.

Soil acid phosphatase activity was measured at 2 and 28 days after the addition of DEM. A modified procedure of Tabatabai (1982) was used for this study. One gram of soil (wet weight) was placed in 15-mL centrifuge tubes with $4 \mathrm{~mL}$ of modified universal buffer (MUB) added. MUB consisted of tris(hydroxymethyl)amino methane, $2.42 \mathrm{~g}$; maleic acid, $2.32 \mathrm{~g}$; citric acid, $2.80 \mathrm{~g}$; boric acid, $1.256 \mathrm{~g} ; 1 \mathrm{M} \mathrm{NaOH}, 97.6 \mathrm{~mL}$; in $1000 \mathrm{~mL}$ final volume with the $\mathrm{pH}$ adjusted to 6.5 with $0.1 \mathrm{M} \mathrm{HCl}$. One $\mathrm{mL}$ of para-nitrophenol phosphate $(0.025 \mathrm{M}$ prepared with MUB buffer) was added to each tube. The tubes were stoppered, vortexed and incubated for one hour at $37^{\circ} \mathrm{C}$. One $\mathrm{mL}$ of $0.5 \mathrm{M} \mathrm{CaCl}_{2}$ and $4 \mathrm{~mL}$ of $0.5 \mathrm{M} \mathrm{NaOH}$ were then added to stop the reaction. The mixtures were centrifuged at $12,000 \times \mathrm{g}$ for $10 \mathrm{~min}$ and the supernatant absorbance measured at $400 \mathrm{~nm}$ with a spectrophotometer. Phosphatase activity was determined by comparing these values to a standard curve prepared with reagent grade para-nitrophenol and expressed as $\mu \mathrm{g}$ of para-nitrophenol produced per gram of soil per hour.

All dehydrogenase and phosphatase activities were measured in triplicate and mean values compared with that of the control soil (not DEM-treated) and expressed as a percent of the control.

\subsection{SOIL INVERTEBRATE MEASUREMENTS}

An earthworm (Eisenia fetida) bioassay system was used to evaluate the toxicity of the DEM. An artificial soil containing $350 \mathrm{~g}$ sand, $100 \mathrm{~g} \mathrm{Kaolin}$ and $50 \mathrm{~g}$ dried peat moss (adjusted to $\mathrm{pH} 6.5$ with $\mathrm{CaCO}_{3}$ ), was used for the earthworm exposures. Worms were fed twice weekly with fermented alfalfa, and soil moisture adjusted to $35 \%$ of dry weight. These soil tests used $70 \mathrm{~g}$ of the artificial soil (placed in $100 \times 25 \mathrm{~mm}$ Petri plates), containing 6 worms. Five replicate plates were used for each test series as noted in the text. The tests were terminated after 12 days, and effects observed over this period. Effects scored included both earthworm mortality and activity. Mass loading or dose was determined on similar soil plates without worms. 


\subsection{STATISTICAL ANALYSIS}

Statistical analyses involved calculation of average \pm SD. Significance was determined using the Student one-tailed t-test (Zar, 1974). 


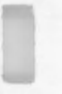

7

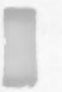

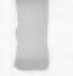

.

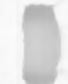

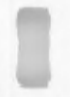

$=$

(1)

]

]

.

(a)

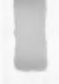

a

.

I 


\subsection{RESULTS AND DISCUSSION}

\subsection{AEROSOL CHARACTERIZATION}

The concentration of DEM aerosols in the exposure chamber were measured by two methods, bubbler and syringe samples, that provided similar results. DEM concentration during the low dose test (DEM-02) was greater than the $150 \mathrm{mg} / \mathrm{m}^{3}$ target value and the concentration during the high dose test (DEM-03) was slightly less than the $1500 \mathrm{mg} / \mathrm{m}^{3}$ target value. This was attributed to possible differences in the droplet/vapor partition between the two aerosols. Deposition velocities to surrogate (glass fiber substrate) surfaces indicated a large relative increase in deposition rate during the high dose test that also supported the conclusion that the droplet/vapor partition was different at low and high DEM aerosol concentration.

\subsubsection{Aerosol Concentration}

Results of bubbler and syringe samples are shown in Tables 3.1 and 3.2. Average concentrations during the two exposure tests were $318 \mathrm{mg} / \mathrm{m}^{3}$ (DEM-02) and $1140 \mathrm{mg} / \mathrm{m}^{3}$ (DEM03). Results of the syringe samples obtained during DEM-02 averaged $420 \mathrm{mg} / \mathrm{m}^{3}$, but were not considered representative of average conditions because they were obtained shortly after 30 sec generation periods, at times when greater than average aerosol concentrations were likely present in the exposure chamber. As generation was continuous during DEM-03, both bubbler and syringe samples were considered representative and were averaged to determine the DEM aerosol mass concentration. The individual average concentrations were $1045 \mathrm{mg} / \mathrm{m}^{3}$ (bubbler) and $1240 \mathrm{mg} / \mathrm{m}^{3}$ (syringe). The single sample obtained during a purge period, B3A during DEM-03, indicated a higher than expected concentration of $1230 \mathrm{mg} / \mathrm{m}^{3}$. This may have been caused by the volatilization of droplets deposited to surfaces within the exposure chamber.

The DEM concentration present during DEM-02 was 2.1 times greater than anticipated, and that during DEM-03 was 1.3 times less than anticipated. This occurred even though the relative generation rate of DEM was $9.7(\sim 10)$ times greater during the high dose test. These results, coupled with observation of droplet mists during both DEM-01 and DEM-03 but not during DEM-02, and deposition rate measurements discussed in the following section, indicated that the partition between droplet and vapor states present in the DEM aerosols was not similar for all tests. It is likely that the vapor phase of the aerosols would deposit to plant, soil, and chamber surfaces at a slower rate than would DEM droplets because the droplets would deposit under the influence of gravitational and diffusional forces not affecting the diffusion of vapor. 
IABLE 3.1 RESULTS OF BUBBLER SAMPLES OBTAINED DURING DEM AEROSOL TESTS

\begin{tabular}{lcccccc}
\hline Test & $\begin{array}{c}\text { Sample } \\
\text { ID }\end{array}$ & $\begin{array}{c}\text { Sample } \\
\text { Period } \\
(\mathrm{min})\end{array}$ & $\begin{array}{c}\text { Gas } \\
\text { Volume } \\
(\mathrm{L})\end{array}$ & $\begin{array}{c}\text { Solvent } \\
\text { Volume } \\
(\mathrm{mL})\end{array}$ & $\begin{array}{c}\text { DEM } \\
\text { Conc. } \\
(\mu \mathrm{g} / \mathrm{mL})\end{array}$ & $\begin{array}{c}\text { DEM Aerosol } \\
\text { Concentration } \\
\left(\mathrm{mg} / \mathrm{m}^{3}\right)\end{array}$ \\
\hline DEM-01 & B1A & 20.0 & 6.7 & 42.3 & 74.9 & 470 \\
& B1B & 20.0 & 6.7 & 46.0 & 0.0 & 0 \\
& B2A & 50.5 & 5.9 & 43.3 & 69.1 & 510 \\
& B2B & 50.5 & 5.9 & 46.8 & 0.0 & 0 \\
DEM-02 & B1A & 7.5 & 4.6 & 42.5 & 26.7 & 250 \\
& B1B & 27.5 & 4.4 & 42.6 & 31.0 & 300 \\
& B2A & 47.5 & 4.3 & 41.5 & 47.1 & 460 \\
& B2B & 65.0 & 2.8 & 44.7 & 16.4 & 260 \\
& & & & & & 850 \\
DEM-03 & B1A & 5.0 & 3.0 & 44.8 & 56.8 & 1270 \\
& B1B & 20.0 & 2.9 & 44.3 & 82.0 & 800 \\
& B2A & 35.0 & 2.9 & 45.4 & 51.3 & 1260 \\
& B2B & 50.0 & 2.8 & 45.1 & 78.2 & 1230 \\
\hline B3A & 65.0 & 2.7 & 45.6 & 73.7 & \\
\hline
\end{tabular}


IABLE 3.2. RESULTS OF SYRINGE SAMPLES OBTAINED DURING DEM AEROSOL TESTS

\begin{tabular}{lcccccc}
\hline Test & $\begin{array}{c}\text { Sample } \\
\text { ID }\end{array}$ & $\begin{array}{c}\text { Sample } \\
\text { Period } \\
(\mathrm{min})\end{array}$ & $\begin{array}{c}\text { Gas } \\
\text { Volume } \\
(\mathrm{mL})\end{array}$ & $\begin{array}{c}\text { Solvent } \\
\text { Volume } \\
(\mathrm{mL})\end{array}$ & $\begin{array}{c}\text { DEM } \\
\text { Mass } \\
(\mu \mathrm{g})\end{array}$ & $\begin{array}{c}\text { DEM Aerosol } \\
\text { Concentration } \\
\left(\mathrm{mg} / \mathrm{m}^{3}\right)\end{array}$ \\
\hline DEM-02 & S1 & 16.0 & 60 & 10 & 27.6 & 470 \\
& S2 & 31.0 & 60 & 10 & 24.4 & 420 \\
& S3 & 41.5 & 60 & 10 & 27.1 & 460 \\
& S4 & 51.5 & 60 & 10 & 19.3 & 330 \\
& & & & & & \\
DEM-03 & S1 & 16.5 & 60 & 10 & 89.6 & 1540 \\
& S2a & 31.5 & 60 & 10 & 72.6 & 1250 \\
& S2b(a) & 31.5 & 60 & 10 & 3.36 & 56 \\
& S2c & 31.5 & 60 & 10 & 0.00 & 0 \\
& S3a & 43.5 & 60 & 10 & 51.5 & 880 \\
& S3b & 43.5 & 60 & 10 & 0.59 & 10 \\
& S3c & 43.5 & 60 & 10 & 0.00 & 0 \\
& S4 & 54.0 & 60 & 10 & 75.8 & 1300 \\
\hline
\end{tabular}

(a) S2b, S2c, S3b, and S3c aerosol concentration results did not include $3 \%$ correction for carry through $\mathrm{h}$ (described in Section 2.2). All other aerosol concentrations do include a multiplying factor of 1.03.

If a greater relative concentration of vapor to droplet mass was present during the low dose test, more of the aerosol would likely be suspended in the exposure chamber and less would be deposited to surfaces. On the other hand, if the greater concentrations present during the high dose tests caused a relative increase in the fractional portion of the aerosol mass consisting of droplets, then deposition rates would increase and aerosol concentrations would be less than those anticipated.

\subsubsection{Deposition Velocity to Surrogate Surfaces}

Rates of DEM aerosol deposition to surrogate glass fiber substrate suspended in the exposure chamber were determined. The average deposition velocities for the low dose (DEM02) and the high dose (DEM-03) tests were $0.00085 \pm 0.00011$ and $0.0066 \pm 0.0018 \mathrm{~cm} / \mathrm{sec}$, respectively. The deposition velocity during the high dose test was 7.8 times greater than that during the low dose test. These results support the speculations of variations in the 
vapor/droplet partition of the DEM aerosols as a function of mass concentration discussed in the previous section.

Rates of deposition to the surrogate surfaces within the exposure chamber were uniform. The variation in the mass of DEM deposited to four deposition coupons during the low dose test was $13 \%$, variation during the high dose test was $27 \%$.

\subsection{MASS LOADING ON AND DEPOSITION VELOCITIES TO FOLIAR SURFACES AND SOILS}

A variety of physical and environmental factors combine to determine the rate at which atmospheric pollutants transfer from the air column, through the near surface boundary layer, to a receptor surface. These factors, which include various atmospheric conditions such as wind speed and humidity, aerosol diameter, vapor pressure, and the physical and chemical structure of the receptor surface, combine to determine the net deposition to a surface. Two different removal mechanisms operate on atmospheric pollutants, one for gas-phase compounds and one for compounds found in the aerosol phase. Although the two deposition mechanisms depend on different parameters, the net deposition to a surface can be calculated when an average gas/aerosol deposition velocity is known. A deposition velocity, which is normally expressed as $V_{d}$ in units of $\mathrm{cm} / \mathrm{sec}$, is analogous to a mass transfer coefficient and describes the rate at which an atmospheric pollutant is deposited on a given surface. Without the deposition velocity, the dosing levels to a receptor surface cannot be predicted.

To quantify the relationship between chemical dosage and damage or effect, the aerosol concentration, deposition velocity, and surface exposure time must all be known to estimate the total surface deposition, or mass loading (ML). Because of the complexity of deposition processes, specific deposition velocities are rarely known, and therefore must be either measured directly or calculated. In this study we have directly measured surface ML by subsampling a known area of an exposed surface, and then extracting and quantifying any deposited chemical species. Subsequently, these data were combined with the measured aerosol concentrations and exposure times to compute the deposition velocity. The formula for calculating $V_{d}$ is presented in Equation 1.

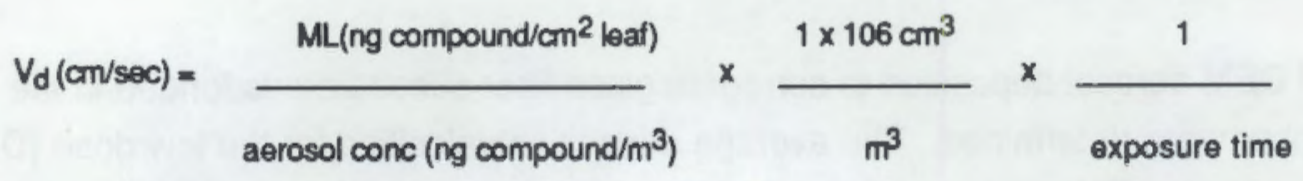


Quantifying the deposition process for specific receptor surfaces permits a comparison of the relative importance of atmospheric variables and canopy and receptor surface (plant and soil) characteristics to the net deposition efficiency. The following subsections discuss the ML of $D E M$ to vegetative and soil surfaces, and the calculated deposition velocities are presented. All reported soil and plant results were obtained from exposure tests DEM-02 $\left(318 \mathrm{mg} / \mathrm{m}^{3}\right)$ and DEM-03 (1145 mg/m $\left.{ }^{3}\right)$.

\subsubsection{Vegetative Surfaces}

Air concentrations of DEM for the low dose exposure averaged $320 \mathrm{mg} / \mathrm{m}^{3}$, while concentrations averaged $1140 \mathrm{mg} / \mathrm{m}^{3}$ for the high dose treatment. Exposure duration was 60 min. Foliar mass loading ranged from 0.2 to $12 \mu \mathrm{g} / \mathrm{cm}^{2}$ in DEM-02, and from 17 to $193 \mu \mathrm{g} / \mathrm{cm}^{2}$ in DEM-03 (Table 3.3). Short-needle pine exhibited the lowest mass loading, while sagebrush and tall fescue had the highest. Differences in mass loading for sagebrush and tall fescue are not significant $(P \geq 0.05)$. Mass loading levels between the high and low dose exposures were substantially higher than the factor of four difference in air concentration, indicating a possible loss at the low dose levels due to volatilization.

Calculated deposition velocities for plant canopies, based on the average air concentration and mass loading levels, are provided in Table 3.3. For the low dose treatment, $V_{d}$ was lowest for the pine $(0.0002 \mathrm{~cm} / \mathrm{sec})$, and a factor of 50 higher for sagebrush and tall fescue $(0.007$ to $0.010 \mathrm{~cm} / \mathrm{sec})$. At higher exposure concentrations, $V_{d}$ values increase by a factor of 3 to 25 . Collection efficiency remains less for the pine than the other two plant species. This is likely related to the canopy structure, and turbulence within the canopies. Differences in deposition velocity for sagebrush and tall fescue are not significant $(P \geq 0.05)$. The lower values for $V_{d}$ at the lower air concentration may be indicative of a higher rate of volatilization at lower mass loading levels. 
IABLE 3.3. AVERAGE FOLIAR MASS LOADING AND DEPOSITION VELOCITIES FOR DEM ON VEGETATIVE SURFACES DURING LOW-AND HIGH-DOSE EXPERIMENTS $(n=3)$

\begin{tabular}{lcc}
\hline Treatment/Species & $\begin{array}{c}\text { Mass Loading } \\
\left(\mu \mathrm{g} / \mathrm{cm}^{2} \pm \mathrm{SD}\right)\end{array}$ & $\begin{array}{c}\text { Deposition Velocity } \\
(\mathrm{cm} / \mathrm{sec} \times 103 \pm \mathrm{SD})\end{array}$ \\
\hline Low Dose (DEM-02) & & \\
Short-Needle Pine & $0.20 \pm 0.12$ & $0.17 \pm 0.11$ \\
Sagebrush & $11.69 \pm 0.54$ & $10.14 \pm 0.47$ \\
Tall Fescue & $8.32 \pm 4.45$ & $7.22 \pm 3.86$ \\
High Dose (DEM-03) & & \\
Short-Needle Pine & $17.08 \pm 2.94$ & $4.16 \pm 0.72$ \\
Sagebrush & $114.79 \pm 29.44$ & $27.97 \pm 7.18$ \\
Tall Fescue & $193.56 \pm 63.41$ & $47.16 \pm 15.45$ \\
\hline
\end{tabular}

\subsubsection{Soil Surfaces}

Soil mass loading levels, following 60 min exposure at the low dose were 45 and 93 $\mu \mathrm{g} / \mathrm{cm}^{2}$ for Burbank and Palouse soil, respectively (Table 3.4). At the high dose level, mass loading levels were approximately $750 \mu \mathrm{g} / \mathrm{cm}^{2}$, and there was no significant difference between soils $(P \geq 0.05)$. As with the foliage, mass loadings in the high dose treatment were approximately 14 times greater than the increase in air concentration between the low and high dose (factor of four). This would again indicate that there is substantial volatilization occurring at low deposition levels.

Deposition velocities calculated for the low dose treatment were $0.04 \mathrm{~cm} / \mathrm{sec}$ and 0.08 $\mathrm{cm} / \mathrm{sec}$ for Burbank and Palouse, respectively. These increased to $0.18 \mathrm{~cm} / \mathrm{sec}$ in the high dose treatment. Again, these values should be similar and independent of air concentration, if no other factor, such as volatilization, were influencing the system. 
IABLE3.4. AVERAGE SOIL MASS LOADING (AND DEPOSITION VELOCITIES) FOR DEM ON SOIL SURFACES DURING THE LOW-AND HIGH-DOSE EXPERIMENTS $(n=3)$

\begin{tabular}{lll}
\hline Treatment/Soil & $\begin{array}{l}\text { Mass Loading } \\
\left(\mu \mathrm{g} / \mathrm{cm}^{2} \pm \mathrm{SD}\right)\end{array}$ & $\begin{array}{l}\text { Deposition Velocity } \\
(\mathrm{cm} / \mathrm{sec} \times 103 \pm \mathrm{SD})\end{array}$ \\
\hline $\begin{array}{c}\text { Low Dose (DEM-02) } \\
\text { Burbank }\end{array}$ & $45.31 \pm 3.26$ & $39.33 \pm 2.83$ \\
Palouse & $93.40 \pm 7.68$ & $81.08 \pm 6.67$ \\
& & \\
High Dose (DEM-03) & & $187.73 \pm 94.12$ \\
Burbank & $770.45 \pm 386.28$ & $176.11 \pm 55.28$ \\
Palouse & $722.77 \pm 226.88$ & \\
\hline
\end{tabular}

\subsection{PHYTOTOXICITY}

\subsubsection{Gross Phytotoxicity}

The determination of foliar toxicity effects can present several problems. While the plants used for this study were of natural genetic stock, individual differences in physiological variability and toxicity response within each test species could be expected to occur. Further, under both field conditions and in the stirred exposure system employed for these studies, where air movement occurs along a given vector (i.e., wind direction), substantial amounts of deposition to canopies can occur irregularly depending on canopy structure and density and the presence of back eddies. Finally, the most cost-effective and consistent manner in which to quantify damage to vegetation must be considered. Taking these issues into account, a nonparametric grading system, a modified Daubenmire rating scale (MDRS) (Daubenmire, 1959), was used as a damage index for the evaluation of contact toxicity.

The criteria used to compile the MDRS are described in Table 2.4. These criteria were used to describe the extent of visual damage to the plants caused by the given exposure period at each concentration of DEM. Damage can be visualized and subjectively quantified using any one or more of the listed symptoms. Also, the intensity of foliar damage can be further quantified by determining the physical length of the needle or leaf damage. The data generated are nonparametric and represent an estimate of foliar damage. 
Table 3.5 provides the gross toxicity data for the three plant species exposed to DEM (foliar exposure only). At the low dose, $320 \mathrm{mg} / \mathrm{m}^{3}$ for $60 \mathrm{~min}$, none of the three plant species exhibited any phytotoxicity following foliar contamination. Neither old nor new growth was affected. At the higher dose, $1140 \mathrm{mg} / \mathrm{m}^{3}$ for $60 \mathrm{~min}$, there was a rapid and severe onset of toxicity. Two days following exposure, chlorosis (Chl), wilting (W), leaf curl (LC) and tip burn/necrosis (TB) were evident. The extent or intensity of damage was most severe in the grass, tall fescue. Sagebrush and short-needle pine were affected to a lesser extent.

IABLE 3.5. PLANT SYMPTOMOLOGY TO DEM EXPOSURE. Symptomology Determined at 2 and 21 Days Post-Exposure.

\begin{tabular}{|c|c|c|c|}
\hline \multirow[b]{2}{*}{ Treatment/Species } & \multirow[b]{2}{*}{$\begin{array}{c}\text { Days } \\
\text { Post-Exposure }\end{array}$} & \multicolumn{2}{|c|}{ Toxicity Response(a) } \\
\hline & & $\begin{array}{l}\text { Damage Index } \\
\text { (DR Scale) }\end{array}$ & Symptomology \\
\hline \multicolumn{4}{|c|}{ Low Concentration (DENM-02) } \\
\hline \multirow[t]{3}{*}{ Tall Fescue } & 0 & 1.0 & O\&NGDH(b) \\
\hline & 2 & 1.0 & O\&NGDH \\
\hline & 21 & 1.0 & O\&NGDH \\
\hline \multirow[t]{3}{*}{ Short-Needle Pine } & 0 & 1.0 & O\&NGDH \\
\hline & 2 & 1.0 & O\&NGDH \\
\hline & 21 & 1.0 & O\&NGDH \\
\hline \multirow[t]{3}{*}{ Sagebrush } & 0 & 1.0 & O\&NGDH \\
\hline & 2 & 1.0 & O\&NGDH \\
\hline & 21 & 1.0 & O\&NGDH \\
\hline
\end{tabular}

(a) Daubenmire Scale and symptomology definitions (Table 2.4).

(b) New growth developing healthy. 
IABLE 3.5. (cont) PLANT SYMPTOMOLOGY TO DEM EXPOSURE. Symptomology Determined at 2 and 21 Days Post-Exposure.

\begin{tabular}{cccl}
\hline & & \multicolumn{2}{c}{ Toxicity Response(a) } \\
\cline { 3 - 4 } Treatment/Species & $\begin{array}{c}\text { Days } \\
\text { Post-Exposure }\end{array}$ & $\begin{array}{l}\text { Damage Index } \\
\text { (DR Scale) }\end{array}$ & Symptomology \\
\hline High Concentration (DEM-03) & & & \\
Tall Fescue & 0 & 3.0 & W \\
& 2 & 6.0 & W, TB (13.0) \\
Short-Needle Pine & 21 & 6.0 & W, Chl, LC, TB (16.0) \\
& 0 & 1.0 & O\&NGDH \\
& 2 & 2.0 & Chl, TB (6.0) \\
Sagebrush & 21 & 3.0 & Chl, TB (5.0) \\
& 0 & 1.0 & O\&NGDH \\
& 2 & 3.0 & LC, W \\
& 21 & 5.0 & Chl, LC, GD \\
\hline
\end{tabular}

(a) Daubenmire Scale and symptomology definitions (Table 2.4).

(b) New growth developing healthy.

Due to the severity of damage from contact toxicity with DEM, residual effects were assessed using tall fescue. The objective of the residual plant effects study was to determine whether there is any lasting effect of foliar toxicants on root systems which were not directly exposed. Control and treated plant canopies were harvested at 30 days post-exposure and dry matter production noted. Cropped plants were allowed to regrow for a second harvest. The results provided in Table 3.6 indicate a significant reduction in biomass following foliar exposure, but only at the high dose treatment. At low dose levels, no residual effect on dry matter production is observed for the second harvest. However, in the high dose treatment a residual effect is apparent, and growth reduction is significantly different than the controls

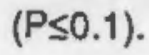


IABLE 3.6. EFFECTS OF DEM ON THE REGROWTH (DRY-MATTER PRODUCTION) OF FOLIARLY EXPOSED TALL FESCUE PLANTS AT 30 AND 60 DAYS POST-EXPOSURE

\begin{tabular}{ll}
\hline \multirow{2}{*}{ Treatment } & \multicolumn{2}{c}{ Dry-Matter Production } \\
\cline { 2 - 2 } & 30 Days Post- Exposure 60 Days Post- Exposure \\
\hline
\end{tabular}

(Avg. g dry wt. \pm variance, $n=2$ )

Control

$1.35 \pm 0.24$

Low Concentration

High Concentration
$1.41 \pm 0.16$ (b)

$0.62 \pm 0.03(\mathrm{c})$
$1.14 \pm 0.09$

$1.11 \pm 0.04(b)$

$0.71 \pm 0.21$

(a) See Table 3.3 for rates of foliar mass loading.

(b) Not significant.

(c) Significant at $P \leq 0.05$ using a one-tailed t-test.

\subsubsection{Metabolic Effects on Plants}

Plant tissues, exposed to $100 \mu \mathrm{g} / \mathrm{mL}$ of DEM for $15 \mathrm{~min}$, failed to show any adverse effects using polarographic methods. Likewise, isolated chloroplast fractions failed to demonstrate any effect of DEM on whole chain or photosystems I or II in vitro. Based on the fact that the foliage of exposed plants, particularly at the high dose level, were heavily contaminated to the point of wetness, and the fact that polarographic methods are unable to be employed at high DEM concentrations, no resolution of the metabolic effects of DEM was possible.

\subsection{EFFECTS ON SOIL MICROBES}

The inhibition of enzymes which drive key metabolic reactions in microbial cells is likely the underlying cause of toxicity of chemicals to the microorganisms. Microbial dehydrogenase enzyme systems catalyze the oxidation of organic material and fulfill an important role in the soil carbon cycle. The assay of soil dehydrogenase activity is a general indicator of the potential activity of the soil microbial population (Skujins,1976). Phosphatases, which can exist extracellularly, are a broad group of enzymes that cleave esters and anhydrides of phosphates from complex organophosphates and are believed to be important in the mineralization of this element from soil organic matter (Ramirez-Martinez,1968). Thus, these two enzyme activities were used in this study to assess DEM toxicity towards soil microorganisms and soil biochemical processes. 
The extent of DEM inhibition of soil enzymatic activities was dependent on soil type, DEM concentration, and length of incubation. The effect of DEM on soil dehydrogenase activity is shown in Table 3.7. Three days after the addition of DEM, dehydrogenase activity in Burbank soil was not affected at DEM concentrations of 25 to $500 \mu \mathrm{g} / \mathrm{g}$ dry soil, but was decreased to $55 \%$ of the control level at $2500 \mu \mathrm{g} / \mathrm{g}$.

\section{IABLE 3.7 THE EFFECT OF DEM ON BURBANK AND PALOUSE SOIL DEHYDRO- GENASE ACTIVITIES}

\begin{tabular}{|c|c|c|c|c|}
\hline \multirow{4}{*}{$\begin{array}{l}\text { DEM Concentration } \\
(\mu g / g)\end{array}$} & \multicolumn{4}{|c|}{ Dehydrogenase Activities \% of Control(a) } \\
\hline & \multicolumn{2}{|c|}{ Burbank Soil } & \multicolumn{2}{|c|}{ Palouse Soil } \\
\hline & \multicolumn{2}{|c|}{ Incubation Time, Days } & \multicolumn{2}{|c|}{ Incubation Time, Days } \\
\hline & 3 & 28 & 3 & 28 \\
\hline 0 & $100(13)$ & $100(6)$ & $100(4)$ & $1000(6)$ \\
\hline 25 & $103(9)$ & $87(12)$ & $146(5)^{*}$ & $104(17)$ \\
\hline 100 & $109(13)$ & $84(4)^{\star(b)}$ & $159(7)^{\star}$ & $116(15)$ \\
\hline 500 & $112(10)$ & $8(9)^{*}$ & $155(4)^{*}$ & 116 (13) \\
\hline 2500 & $55(7)^{\star}$ & $77(5)^{*}$ & $44(3)^{*}$ & $77 \quad(9)$ \\
\hline
\end{tabular}

(a) Mean ( \pm standard deviation), $n=3$.

(b) "Denotes significantly different from control ( $0 \mu g$ DEM/g dry soil) based on student's t-test, $P \leq 0.05$.

After 4 weeks' incubation time, DEM concentration greater than $100 \mu \mathrm{g} / \mathrm{g}$ caused inhibition in dehydrogenase activity, however, the degree of impact decreased to $77 \%$ at the highest DEM concentration tested. In Palouse soil, soil dehydrogenase activity was substantially enhanced (146-159\% of control) 3 days after the addition of DEM at concentrations of 25 to $500 \mu \mathrm{g} / \mathrm{g}$, but was inhibited to $44 \%$ by $2500 \mu \mathrm{g} / \mathrm{g}$ DEM concentration. However, the impact was transient in nature, with recovery to the level of control soil after 28 days. The only exception was with the $2500 \mu \mathrm{g} / \mathrm{g}$ treatment, which remained inhibited. The $\mathrm{EcD}_{50}$, an expression of the ecological dose of DEM causing $50 \%$ inhibition (Babich et al., 1983), were calculated from response curves in Figure 3.1. For both Burbank and Palouse soils, the $\mathrm{ECD}_{50}$ after 3 days incubation was roughly $2500 \mu \mathrm{g} / \mathrm{g}$ and after 28 days incubation, it increased to greater than $2500 \mu \mathrm{g} / \mathrm{g}$, indicating a recovery trend as a function of time for soil dehydrogenase activity. 


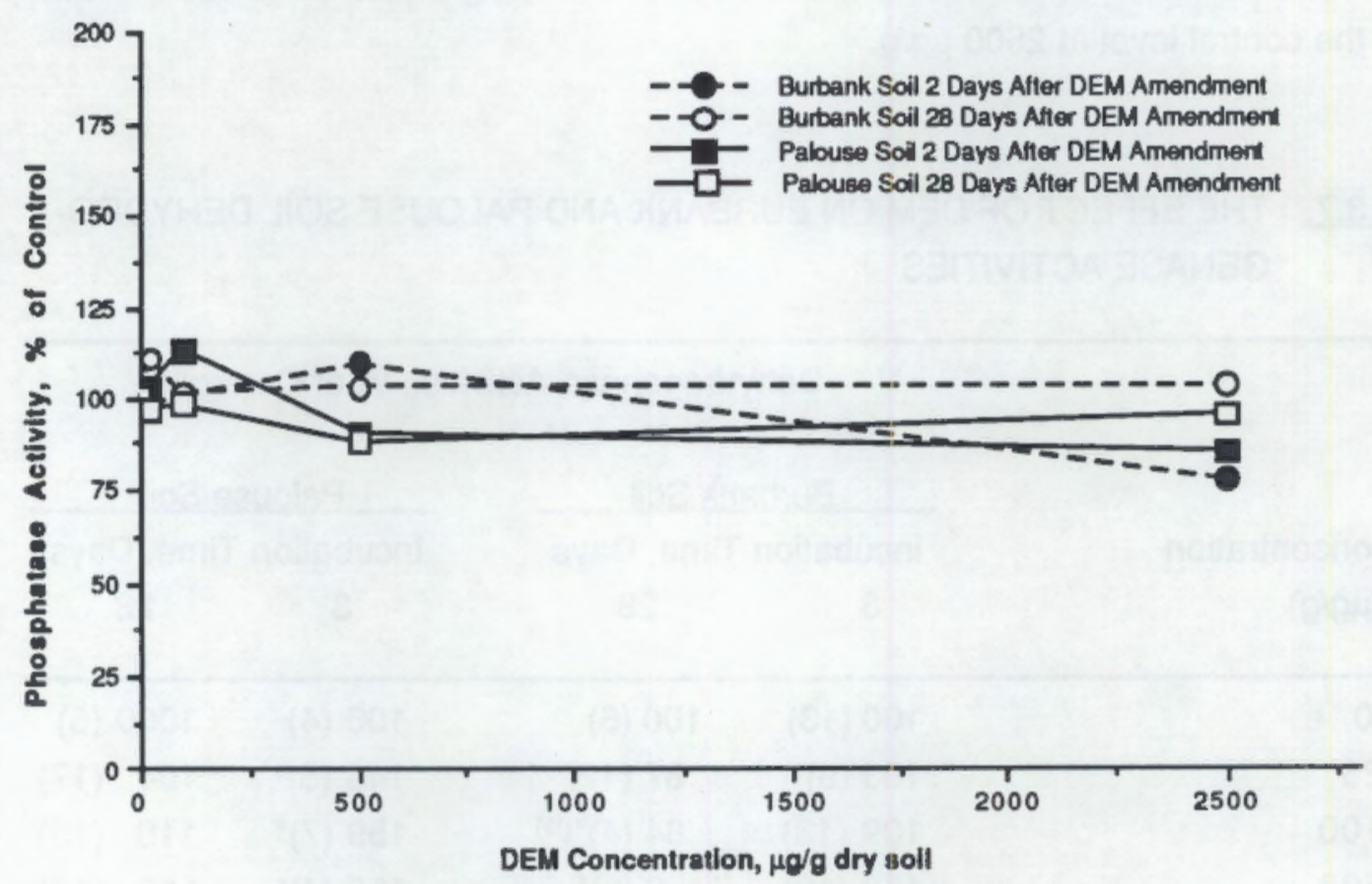

\section{FIGURE 3.1. RESPONSE CURVE FOR THE EFFECT OF DEM ON BURBANK AND PALOUSE SOIL DEHYDROGENASE ACTIVITIES}

Soil phosphatase activity was not affected by DEM at $25-500 \mu \mathrm{g} / \mathrm{g}$. Only at concentration of $2500 \mu \mathrm{g} / \mathrm{g}$, did soil phosphatase activity decline moderately to $78 \%$ in Burbank soil and to $85 \%$ in Palouse soil. However, after 28 days, activity recovered to the level of control soil (Table 3.8). Curves illustrated in Figure 3.2 indicated that $E_{C D} D_{50}$ of DEM on soil phosphatase is far greater than the highest DEM concentration tested $(2500 \mu \mathrm{g} / \mathrm{g})$. $E \mathrm{CD}_{50}$ at day 28 appeared to be higher than at day 2, again indicating a recovery trend as a function of time for soil phosphatase activity. 
IABLE 3.8. THE EFFECT OF DEM ON BURBANK AND PALOUSE SOIL PHOSPHATASE ACTIVITIES

\begin{tabular}{|c|c|c|c|c|}
\hline \multirow{4}{*}{$\begin{array}{l}\text { DEM Concentration } \\
\qquad(\mu \mathrm{g} / \mathrm{g})\end{array}$} & \multicolumn{4}{|c|}{ Dehydrogenase Activities \% of Control(a) } \\
\hline & \multicolumn{2}{|c|}{ Burbank Soil } & \multicolumn{2}{|c|}{ Palouse Soil } \\
\hline & \multicolumn{2}{|c|}{ (Incubation Time, Days) } & \multicolumn{2}{|c|}{ (Incubation Time, Days) } \\
\hline & 2 & 28 & 2 & 28 \\
\hline 0 & $100(9)$ & $100(4)$ & $100(4)$ & $100(0.4)$ \\
\hline 25 & 98 (11) & $111(11)$ & $103(3)$ & 97 (4) \\
\hline 100 & $101(10)$ & $102(4)$ & $113(4)^{*}$ & $98 \quad(9)$ \\
\hline 500 & $110(9)$ & $103(14)$ & $91(3)^{*}$ & $88(6)$ \\
\hline 2500 & $78(7)^{*(b)}$ & $104(4)$ & $85(4)^{*}$ & 96 (2) \\
\hline
\end{tabular}

(a) Mean ( \pm standard deviation), $n=3$.

(b) Denotes significantly different from control ( $0 \mu \mathrm{g}$ DEM/g dry soil) based on Student's t-test, $P \leq 0.05$ 


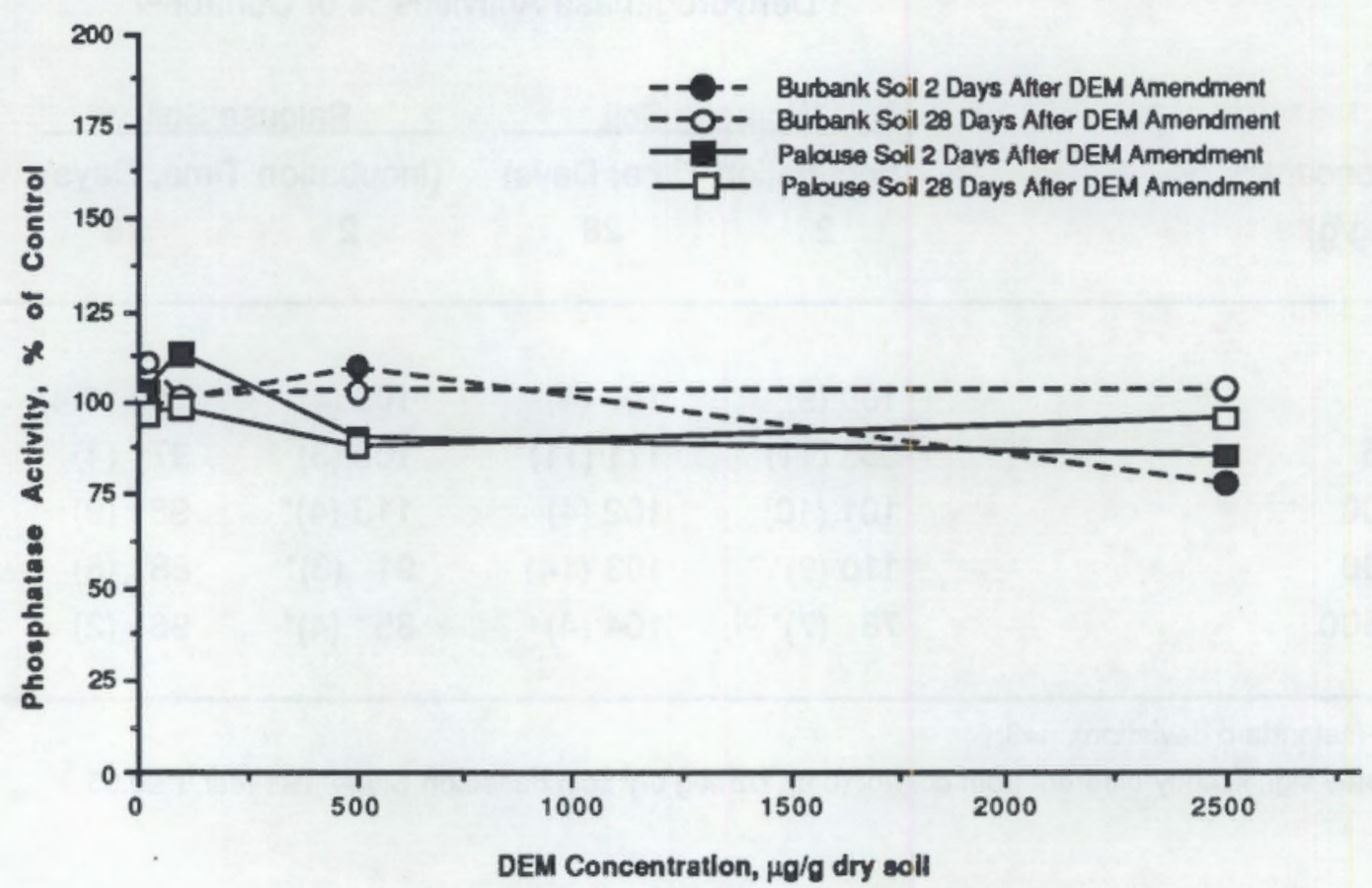

EIGURE 3.2. RESPONSE CURVE FOR THE EFFECT OF DEM ON BURBANK AND PALOUSE SOIL PHOSPHATASE ACTIVITIES

The data show that, in general, concentrations of DEM at 25 to $500 \mu \mathrm{g} / \mathrm{g}$ do not significantly impact soil enzymatic activities. Activities were slightly impacted only at concentrations greater than 500 or $2500 \mu \mathrm{g} / \mathrm{g}$. In fact, Palouse soil phosphatase activity was enhanced by DEM at $25-500 \mu \mathrm{g} / \mathrm{g}$. Both soil dehydrogenase and phosphatase activities recovered to the level of control soil after 28 days, indicating the effect was not persistent. The aliphatic structure of $\mathrm{DEM}[\mathrm{CH} 2(\mathrm{COOC} 2 \mathrm{H} 5) 2]$ suggests this compound will likely be degraded by soil microorganisms and enhance microbial activities at low concentrations; but becomes toxic at concentrations higher than $2500 \mu \mathrm{g} / \mathrm{g}$. 


\subsection{TERRESTRIALPERSISTENCE}

\subsubsection{Persistence of DEM in Soil}

Soils contaminated in the high dose test for 60 min were sampled at intervals over a 4-day period. Samples were extracted for total DEM and the environmental half-life determined. Data points were plotted, and regressions performed to determine loss rates. The depuration plots of DEM in both Palouse (Figure 3.3) and Burbank soil (Figure 3.4) were biphasic. Halftimes for Palouse were 2 and $16 \mathrm{~h}$; while for Burbank soil half-times were 1.2 and $5.4 \mathrm{~h}$. Since DEM has a significant vapor pressure, volatilization likely accounts for the observed losses. After 4 days, of the $750 \mu \mathrm{g} \mathrm{DEM} / \mathrm{cm}^{2}$ deposited to soils, only $2 \mu \mathrm{g} \mathrm{DEM} / \mathrm{cm}^{2}$ remains in the Palouse soil. In Burbank, less than $0.1 \mu \mathrm{g} / \mathrm{cm}^{2}$ remains after 4 days.

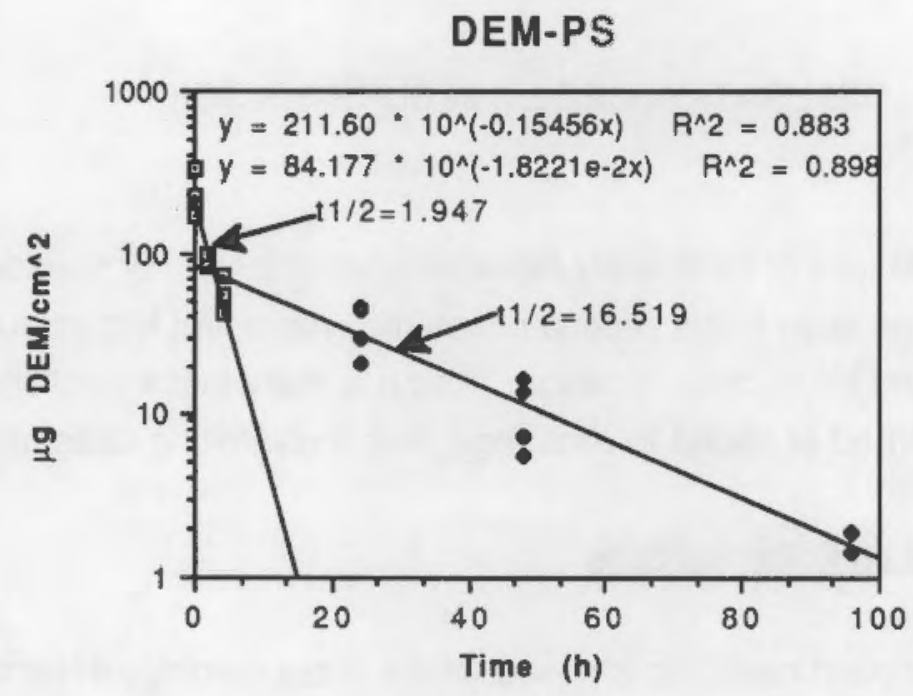

FIGURE 3.3. DEPURATION OF DEM IN PALOUSE SOIL 


\section{DEM-BS}

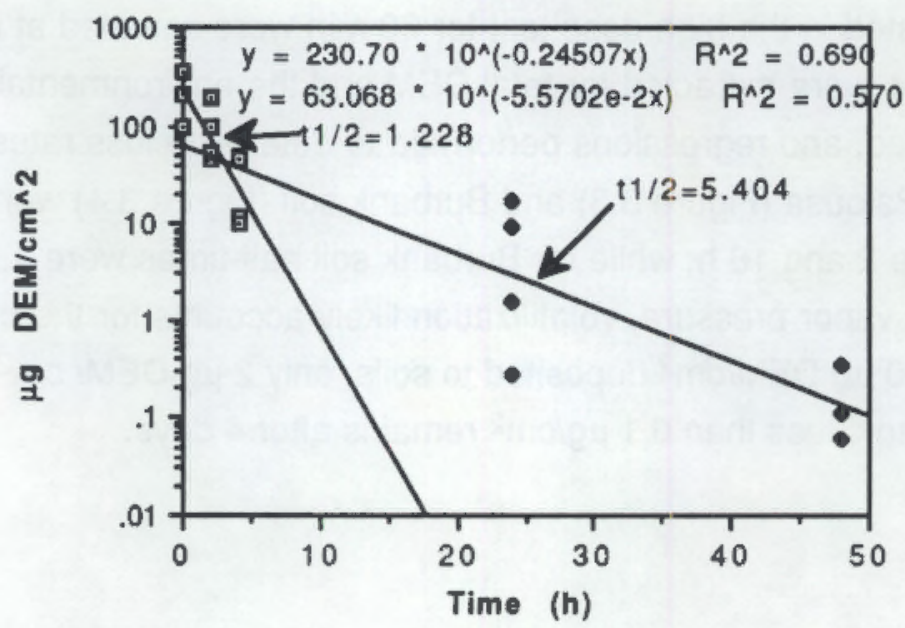

EIGURE 3.4. DEPURATION OF DEM IN BURBANK SOIL

While the initial rapid loss of DEM likely represents volatilization of surface deposited material, the slower loss rate seen in the second phase may represent losses due to both volatilization, and abiotic and biotic decomposition. Also it is likely that a fraction of the deposited DEM may be sorbed or bound to exchange sites thus limiting rates of volatilization.

\subsubsection{Persistence of DEM on Foliar Surfaces}

Depuration rates for plant canopies is based on the mass loadings determined for DEM03, the high dose treatment (Figure 3.5.). As with the soils, depuration of DEM from contaminated foliar surfaces is biphasic. The rapid loss phase has a half-time of 1 to $3 \mathrm{~h}$ for sagebrush, tall fescue and short-needle pine. The longer depuration component had half-times of 17,45 and $242 \mathrm{~h}$, for tall fescue, sagebrush and pine, respectively. After 4 days, only 1 to $3 \mu \mathrm{g}$ $\mathrm{DEM} / \mathrm{cm}^{2}$ remains associated with foliar surfaces. It is likely that the surface composition of foliar surfaces, waxes and cutin, affect sorption and thus subsequent volatilization of DEM. 

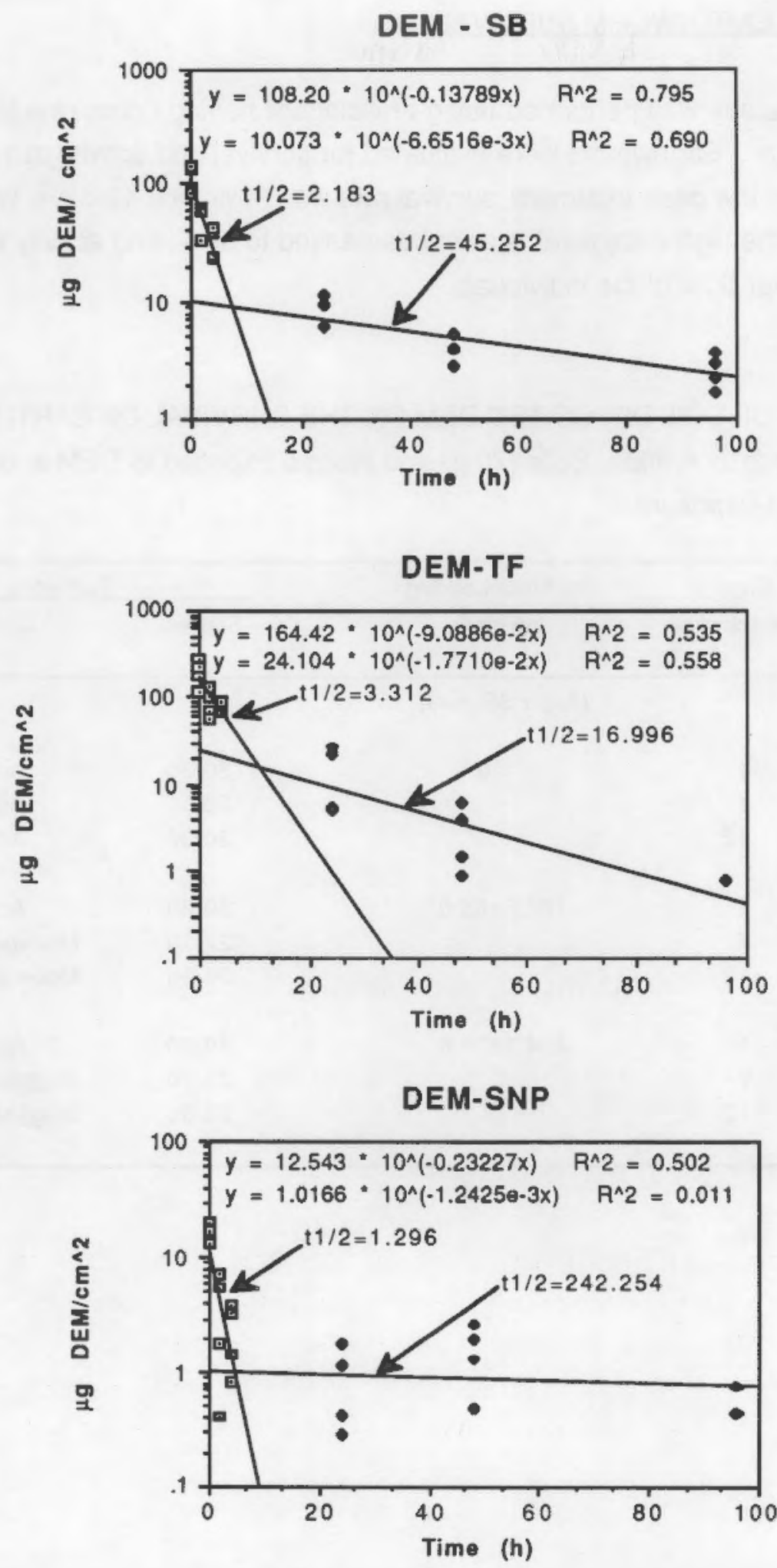

FIGURE 3.5. DEPURATION OF DEM DEPOSITED TO PLANT CANOPIES OF SAGEBRUSH (SB), TALL FESCUE (TF), AND SHORT-NEEDLE PINE (SNP) 


\subsection{EFFECT OF DEM ONEARTHWORM SURVIVAL}

The earthworm bioassay was performed using artificial soil having contamination doses of 107 and $204 \mu \mathrm{gDEM} / \mathrm{cm}^{2}$. Earthworms were evaluated for survival and activity at 1, 7 and 12 days post-exposure. In the low dose treatment, survival rate was $86 \%$ after 12 days, with a slight overall loss in activity. At the high dose level, survival decreased to $66 \%$, and activity was judged to be affected in over $50 \%$ of the individuals.

IABLE 3.9. INFLUENCE OF SOIL DEPOSITED DEM ON THE SURVIVAL OF EARTHWORMS (Eisenia foetida). Artificial Soils $(70 \mathrm{~g})$ and Worms Exposed to DEM and Held for 12-Days Post-Exposure.

\begin{tabular}{|c|c|c|c|c|}
\hline \multirow[b]{2}{*}{ Treatment } & \multirow{2}{*}{$\begin{array}{l}\text { Days } \\
\text { ost-Exposure }\end{array}$} & \multirow{2}{*}{$\begin{array}{l}\text { Soil Mass Loading } \\
\qquad\left(\mu \mathrm{g} / \mathrm{cm}^{2}\right)\end{array}$} & \multicolumn{2}{|c|}{ Earthwom } \\
\hline & & & Survival & Condition \\
\hline & & (Avg $\pm S D, n=3$ ) & & \\
\hline \multirow[t]{3}{*}{ Control } & 1 & 0 & $30 / 30$ & Active \\
\hline & 7 & & $30 / 30$ & Active \\
\hline & 12 & & $30 / 30$ & Active \\
\hline \multirow[t]{3}{*}{ Low Concentration (DEM-02) } & 1 & $107.5 \pm 65.0$ & $30 / 30$ & Active \\
\hline & 7 & & $27 / 30$ & Moderately Active \\
\hline & 12 & & $26 / 30$ & Moderately Active \\
\hline \multirow[t]{3}{*}{ High Concentration (DEM-03) } & 1 & $204.1 \pm 39.6$ & $30 / 30$ & Active \\
\hline & 7 & & $23 / 30$ & Sluggish to Active \\
\hline & 12 & & $20 / 30$ & Sluggish to Active \\
\hline
\end{tabular}




\subsection{CONCLUSIONS}

Analysis of the results from the low and high air concentration test generations indicates that air concentrations of DEM will influence the proportion of aerosolized material that persists in the liquid droplet versus gaseous state. Thus, the vapor pressure of DEM is high enough to result in mixed gas and liquid phases, and in the low dose test vapor dominated, while in the high dose test liquid droplets dominated. This affected the overall rate of deposition to surfaces. Deposition velocities for DEM to soil surfaces ranged from 0.04 to $0.2 \mathrm{~cm} / \mathrm{sec}$, for low and high air concentrations. For foliar surfaces, deposition velocities ranged from $0.0002 \mathrm{~cm} / \mathrm{sec}$ at low air concentrations to $0.05 \mathrm{~cm} / \mathrm{sec}$ for high dose levels. Collection efficiency was lowest for shortneedle pine and greatest for sagebrush and tall fescue.

The volatility of DEM results in a rapid loss from soil and foliar surfaces. The residence times or half-lives of DEM deposited to soils was $2 \mathrm{~h}$ for the fast component and 5 to $16 \mathrm{~h}$ for the residual material. DEM deposited to foliar surfaces also exhibited biphasic depuration. The half-life of the short residence time component ranged from 1 to $3 \mathrm{~h}$, while the longer time component had half-times of 16 to $242 \mathrm{~h}$. Volatilization and other depuration mechanisms reduce surface contaminant levels in both soils and foliage to less than $1 \%$ of initial dose within $96 \mathrm{~h}$.

DEM is not phytotoxic at foliar mass loading levels of less than $10 \mu \mathrm{g} / \mathrm{cm}^{2}$. However, severe damage is evident at mass loading levels in excess of $17 \mu \mathrm{g} / \mathrm{cm}^{2}$. Tall fescue and sagebrush were more affected than was short-needle pine, however, mass loading levels were markedly different. Regrowth of tall fescue indicated that the effects of DEM are residual, and growth rates are affected at higher mass loadings through the second harvest. At higher dose levels in vitro studies failed to indicate any effects of DEM on photosynthesis/respiration or electron transport at solution concentrations of $100 \mu \mathrm{g} / \mathrm{mL}$.

Results from in vitro testing of DEM indicated concentrations below $500 \mu \mathrm{g} / \mathrm{g}$ dry soil generally did not negatively impact soil microbial activity. In fact, Palouse soil dehydrogenase activity was initially enhanced by the addition of DEM at $25-500 \mu \mathrm{g} / \mathrm{g}$. Short-term effects of DEM (2-3 days incubation) were more profound on soil dehydrogenase activity $\left(E D_{50}=2500 \mu \mathrm{g} / \mathrm{g}\right)$ than on soil phosphatase activity $\left(E_{50}>2500 \mu \mathrm{g} / \mathrm{g}\right)$, indicating soil dehydrogenase is more susceptible to DEM than soil phosphatase. However, no enzyme inhibition or enhancement was observed after $\mathbf{2 8}$ days incubation, indicating the effect is transient in nature with a possibility of recovery. Although in vitro testing usually gives a good indication of dose response and may be representative of a field exposure, spill or waste disposal situation, it is 
not a true representation of actual aerosol deposition. Factors such as volatility, mass loading, wind speed and relative humidity can vary so that when used as a simulant for environmental testing, the influence of DEM on soil microbial and biochemical activity may be different following an actual depositional event.

Results of the earthworm bioassay indicate survival to be 86 and $66 \%$ at soil doses of 107 and $204 \mu \mathrm{g} \mathrm{DEM} / \mathrm{cm}^{2}$, respectively. At higher dose level, activity or mobility was judged to be affected in over $50 \%$ of the individuals. 


\subsection{SUALITY ASSURANCE AND QUALITY CONTROL}

At Pacific Northwest Laboratory (PNL), quality control (OC) is "the system of activities to provide a quality product," and quality assurance (QA) is "the system of activities to provide assurance that the quality control system is performing adequately." The prime responsibility for QAVC is placed on the Program Manager, Principal Investigator, and the Task Leaders; however, the QA audit function is maintained outside of the project and is not directly supported by the project. This audit function is performed by Rob Cuello, the Earth and Environmental Sciences Center's senior Quality Assurance Officer, and is outside the control of the Program Manager or the Principal Investigator.

\subsection{QUALITY ASSURANCE}

The objective of the QA program for the wood pole study is to ensure that the production of data are precise and accurate (within the stated acceptance criteria), representative, comparable, traceable, and defensible. To ensure these conditions are met, PNL's quality assurance program is envisioned to consist of the following elements:

- Procedure review and approval [of Standard Operating Procedures (SOP's)]

- Personnel training

- Pretest preparation

- Quality Control of sampling function and analysis function

- QA audits

- Feedback and corrective action (if necessary).

\subsection{QUALITY ASSURANCE TRAINING}

The activities of the QA training program include: introducing personnel to the QA program, identifying training elements, preparing and training supervisory and test personnel, implementing QA audits, and conducting refresher QC training or on-the-job training as needed.

The project team will review the procedures that govern the collection and interpretation of field and/or laboratory data and will familiarize themselves with what audit procedures are to be used. Supervisory personnel will require some training to become knowledgeable of the QA procedures to be employed. 


\subsection{PROCEDURE REVIEW AND APPROVAL (SOP)}

Quality control guidelines for a particular program are developed by the Task Leaders and approved by the Principal Investigator for all standard operating procedures (sampling, analysis and reporting), instruction, specifications, equipment, and so forth. All SOP's for sampling and analysis are described in writing, and each procedure is reviewed to determine what quality control steps will be incorporated. Each team member will use the procedures outlined in the SOP's to prevent contamination, to provide the proper size sample, to assure proper taxonomic identification, to provide proper kind and number of blanks, to maintain standardization of measuring equipment, and to guarantee the keeping of useable records.

Quality assurance also ensures that the documentation system provides for and maintains a current configuration (latest revision) of procedures being used on the program. Whenever it is evident that data being obtained are not sufficiently accurate or appropriate for the intent of the program, the sampling and/or analytical SOP must be modified after the review and approval by the Project Manager. The modifications are then incorporated into the revised SOP's.

\subsection{LABORATORY RECORD BOOKS}

Work performed on any given project are documented in laboratory record books issued to the project personnel. Permanent records on each book are maintained by PNL and include the project number under which the book was issued, the Record Book number, and the name of the staff member to whom the book was issued. A signature sheet for each record book is kept on file with PNL, and an assignment form inside the front cover of the book is used to indicate the project work number and the individual to whom the book was assigned. Staff members assume full responsibility for the use and security of the books while the books are in their possession. At the end of the project, the books are returned to PNL for archiving.

\subsection{SAMPLE IDENTIEICATION AND TRACEABILITY}

A system of accountability is used to control the number and variety of samples and the quality of data generated on a research project. The Principal Investigator helps design the initial system and, since he or she works most closely with the experiments, helps monitor the system's effectiveness. Quality assurance at this stage of the project is used to assure that the samples are complete and appropriate. Therefore, the QA officer has the following responsibilities: 
- Participate in the development of a system for keeping records of samples and for introducing proper QA steps to assure dependability of the system.

- Review sample log system and implementation forms. (The forms provide information on samples collected and indicate the work to be done on the samples.)

- Monitor the sample identification system to ensure proper labeling of samples, proper dispersements of samples for analysis, and proper quality control of spikes, blanks, and duplicates.

The Principal Investigator and the Task Leaders are responsible for seeing that the documentation is done either by themselves or by the team members. A team member is usually assigned the responsibility of handling the samples and storing, retrieving, dispersing, and maintaining records of those samples.

\subsection{QUALITY CONTROL}

The key quality control operations that may be emphasized in a particular program are procurement $Q A$, standardization/calibration, sampling, and analysis.

\subsection{PROCEDURE OUALITY CONTROL}

Task Leaders are responsible for ensuring that all procured materials (e.g., samples, collection containers) conform to appropriate specifications. They also are responsible for ensuring that reagents and chemicals with limited shelf life are identified and used within the specified expiration date.

\subsection{SAMPLING QUALITY CONTROL}

A sampling information document developed by the Task Leader is used to detail the kind of samples to be taken, the locations where samples are taken, the time and duration of sampling, the size of samples to be taken, and other pertinent information on the conditions that are useful to the sampling team. From this information, the sampling team will select the labor hours and apparatus necessary to carry out the sampling task and will follow the appropriate SOP. 
The sampling team then develops a QA plan that includes:

- sampling information forms

- lists of apparatus, reagents, supplies

- pre-sampling calibrations

- on-site checks of apparatus

- post-sampling calibrations.

\subsection{ANALYTICAL OUALITY CONTROL}

Analytical quality is monitored through function checks and control checks. Function checks are performed by the analyst to verify the stability and validity of the sample and the performance of the analytical equipment. Sample validity is assessed in terms of spoilage, container integrity, amount of specimen, sample identification, sample blanks, and other general appearance such as condition of filters or uniformity of sample collections across a filter.

The analytical equipment is checked in terms of calibration and performance of calibrating standards; the latter is part of the permanent record of the analysis. It is recommended that calibration standards that span the working range in factors of two should be run through the entire analysis system at least four times. This develops information on precision and detection limits where appropriate.

Control checks are made by analyzing samples provided by the Task Leader. These samples include blanks, duplicates, spikes, and, if available, standard reference materials in quantities that depend on the total number of samples assigned and on the level of accuracy needed in the analysis. These control samples are introduced into the system in such a manner that the analyst will not give them particular attention.

As a rule, large batches of samples (25 samples or more) should have a control (spike, blank, or replicate) sample in every five samples. A small batch of samples (up to five samples) may have more control samples than real samples.

For large and continuous amounts of samples, control charts of performance of duplicates and spikes must be maintained. This allows the analyst and Task Leader to know when the system is out of control, which part of the system is the probably cause, and when and what corrective action is to be taken. 


\subsection{EXPERIMENTALPROTOCOLS}

\section{Study Component: CHEMICAL ANALYSIS OF DIETHYL MALONATE}

Purpose: A method was developed to permit rapid and selective analysis of diethyl malonate in a variety of matrices. The method developed utilized dimethyl malonate as an internal standard for the quantification of diethyl malonate. Components were separated by capillary gas chromatography and detected by mass spectrometry operated in the selected ion monitoring acquisition mode.

Analytical Method: The GC/MS method employed a Hewlett Packard 5890A capillary gas chromatograph interfaced with a Hewlett Packard 5970A mass spectrometer. Separations were conducted on a $30 \mathrm{~m} \times 0.255 \mathrm{~mm}$ i.d. DB-Wax column ( $\mathrm{J} \& \mathrm{~W}$ Scientific, Folsom, CA) containing a $0.25-\mu \mathrm{m}$ film of stationary phase. The polar polyethylene glycol stationary phase was cross-linked and bonded with the fused silica surface to provide for greater thermal stability as well as to minimize phase stripping during splitless injections. Sample extracts $(1.0 \mu \mathrm{L})$ were introduced to the column in the splitless mode with a loading time of $0.6 \mathrm{~min}$. After an initial hold at $40^{\circ} \mathrm{C}$ for $2 \mathrm{~min}$, the column was temperature programmed at a rate $66^{\circ} \mathrm{C} / \mathrm{min}$ to a final temperature of $220^{\circ} \mathrm{C}$.

Method Calibration: Quantification of diethyl malonate was accomplished by the internal standard method utilizing dimethyl malonate as the internal standard. Data acquisition was in the selected ion mode which had the advantage of increasing the selectivity and sensitivity of the analysis over the normal scanning acquisition mode. Masses were selected on the basis of comprising major fragmentation ions that were free from matrix interferences. Based on these criteria, $\mathrm{m} / \mathrm{e}$ of 101 (specific for dimethyl malonate) and $\mathrm{m} / \mathrm{e}$ of 115 (specific for diethyl malonate) were chosen. Data acquisition for these ions was at an electron multiplier voltage of 2200 volts with a dwell time of $100 \mathrm{~m} / \mathrm{sec}$. A standard curve was generated by spiking diethyl malonate standards with a constant concentration of internal standard and subjecting these samples to analysis under the conditions described above. By plotting the ratio of the integrated peak areas of the diethyl malonate to that of the internal standard as a function of diethyl malonate concentration, a standard calibration curve was obtained. Comparison of the ratio of diethyl malonate to internal standard integrated peak areas in the sample extracts to the standard curve formed the basis for quantification during this study. 
Sample Preparation: Methylene chloride extracts of plant tissues, soils, deposition coupons, and air samples were immediately transported to the chemical analysis laboratory where they were promptly spiked with internal standard. Samples containing the internal standard were transferred to autosample vials fitted with Teflon- lined caps and analyzed for diethyl malonate without further manipulation.

\section{Study Component: QUANTIFICATION OF PLANT METABOLIC EFFECTS OF CHEMICAL SIMULANTS}

Purpose: The phytotoxicity of CEES on whole plants was investigated using in vitro systems. These included: 1) the effects of the simulant on photosynthesis (oxygen evolution) and dark respiration (oxygen uptake) in intact leaf segments; and 2) the effects of the simulant on specific photochemical reactions and electron transport chains in isolated chloroplasts.

\section{Analytical Methods:}

\section{Whole Leaf Measurements}

Leaf samples from the different species exposed at high and low concentrations of the chemical were taken prior to, immediately following, and at several intervals after exposure for analysis of oxygen evolution and uptake. Leaves were excised from the plants, placed in moistened paper towels, and maintained at $4^{\circ} \mathrm{C}$ until assayed. They were then wet with distilled water and sliced with a razor blade into pieces $<5 \mathrm{~mm}$ in length or diameter. The pieces were transferred to an assay medium consisting of 2 $\mathrm{mM} \mathrm{CaCl}_{2}, 10 \mathrm{mM}$ sodium bicarbonate, and $20 \mathrm{mM}$ HEPES pH 7.6. Paired tissue samples were taken from this solution and placed directly into paired, water-jacketed ( $3.9 \mathrm{~mL}$ of control media at $20^{\circ} \mathrm{C}$ ) cuvettes. The suspension was continually stirred with magnetic stirrers. The cuvettes were then covered with aluminum foil for dark respiration for approximately $25 \mathrm{~min}$ until a steady-state rate was obtained. They were then illuminated with saturating light ( $>1200 \mu$ Einsteins min $^{-2} \mathrm{~s}^{-1}$ ) at $600 \mathrm{~nm}$ for an additional $\mathbf{2 0} \mathrm{min}$ to obtain a steady-state rate of photosynthesis. After illumination, the tissues were removed from the cuvettes, and blotted and dried overnight in a $75^{\circ} \mathrm{C}$ oven so the dry weight could be obtained. Assays were run in triplicate and the data expressed as $\mu \mathrm{Mol} \mathrm{O}_{2} \mathrm{~h}^{-1} \mathrm{~g}$ dry $\mathrm{wt}^{-1}$. 
Isolated Chloroplast Measurements

Chloroplasts were isolated from commercially obtained spinach (Spinacea oleracea) leaves according to the methods of Walker (1980). Approximately $80 \mathrm{~g}$ of leaves with the mid-ribs removed were washed with distilled water and chilled prior to grinding. The leaves were then ground for $10 \mathrm{sec}$ with a sorvall tissue homogenizer in $50 \mathrm{~mL}$ of grinding medium, consisting of $0.33 \mathrm{M}$ sorbitol; $10 \mathrm{mM} \mathrm{Na}_{4} \mathrm{P}_{2} \mathrm{O}_{7} ; 5 \mathrm{mM} \mathrm{MgCl}_{2}$; and $2 \mathrm{mM}$ sodium ascorbate, $\mathrm{pH} 6.5$ which had been chilled to a slush-like consistency to maintain the grinding temperature around $4^{\circ} \mathrm{C}$. The ground material was then filtered through 8 layers of cheesecloth and the filtrate immediately centrifuged at $1500 \times \mathrm{g}$ for 90 sec. The supernate was then decanted and the surface of the pellet washed with 1 $\mathrm{mL}$ of resuspension mix which was then discarded. The pellet was resuspended in a mixture consisting of $0.3 \mathrm{M}$ sorbitol; $2 \mathrm{mM} \mathrm{Na} 2 \mathrm{EDTA} ; 1 \mathrm{mM} \mathrm{MgCl} ; 1 \mathrm{mM} \mathrm{MnCl} 2 ; 50$ $\mathrm{mM}$ HEPES; $10 \mathrm{mM}$ f; $5 \mathrm{mM} \mathrm{PPi} ; 0.5 \mathrm{mM}$ Pi, pH 7.6. Chlorophyll content was determined according to the method of Arnon (1949): $50 \mu \mathrm{L}$ of the chloroplast suspension was added to $20 \mathrm{~mL}$ of $80 \%(\mathrm{v} / \mathrm{v})$ acetone and filtered (through No.1 Whatman paper), and the absorbance read at $652 \mathrm{~nm}$. Nine divided by the absorbance gives the volume of the original suspension containing $100 \mu \mathrm{g}$ of chlorophyll. All procedures were carried out under low light and at $4^{\circ} \mathrm{C}$.

\section{Photochemical Assays}

Assays were conducted on PS II, PS I, and whole-chain electron transport, measuring oxygen evolution and uptake with a Clark-type electrode (YSI Instruments) in a $1.8-\mathrm{mL}$ volume, water-jacketed cuvette (Gilson Medical Electronics) maintained at $20^{\circ} \mathrm{C}$. Stock solution of the CEES was prepared so that addition of $100 \mu \mathrm{L}$ would equal a final concentration within the cuvette of 1 or $10 \mathrm{ppm}$. All assays were conducted in paired cuvettes at the same time, with one cuvette serving as a control and the other containing the simulant. The CEES was either added directly to the cuvette prior to illumination ( $1 \mathrm{~min}$ ) or to a chloroplast suspension in a test tube for $1 \mathrm{~h}$ prior to transfer to the cuvette for assay. Control chloroplasts were treated in the same manner. Assays were run in triplicate, and all data are expressed in either $\mu \mathrm{Mol}_{2}$ $\mathrm{h}^{-1} \mathrm{mg}^{-1} \mathrm{chl}$ or as \% control of the paired assay. The analyses of the three components of the chloroplast electron transport system were performed according to the following methods:

PS II Measurements: Assays were conducted according to the methods of Boyer and Bowen (1970). The assay medium ( $1.8 \mathrm{~mL}$ ) consisted of $0.33 \mathrm{M}$ sorbitol; $2 \mathrm{mM} \mathrm{Na} 2$ EDTA; 1 
$\mathrm{mM} \mathrm{MgCl} ; 1 \mathrm{mM} \mathrm{MnCl} 2$; and $50 \mathrm{mM}$ HEPES, $\mathrm{pH}$ 7.6. Sodium 2,6dichloroindophenol (DCIP), $0.88 \mathrm{mM}$, was added just prior to the addition of chloroplasts $(100 \mu \mathrm{g})$. The suspension was then illuminated from the side with saturating light (>1200 $\mu$ Einsteins $\left.\mathrm{min}^{-2} \mathrm{~s}^{-1}\right)$ at $600 \mathrm{~nm}$, and the rate of oxygen evolution determined from the initial slope of the electrode output as a function of time.

PS I Measurements: Assays were conducted according to the methods of Keck and Boyer (1974). The assay medium consisted of $1 \mathrm{mM} \mathrm{ADP}, 1 \mathrm{mM} \mathrm{K}_{2} \mathrm{HPO}_{4}, 0.1 \mathrm{M} \mathrm{KCl}, 5 \mathrm{mM}$ $\mathrm{MgCl}_{2}, 0.1 \mathrm{mM}$ DCMU, $80 \mu \mathrm{M}$ DCIP, $1 \mathrm{mM}$ sodium ascorbate, $0.5 \mathrm{mM}$ methyl viologen (MV), $0.5 \mathrm{mM}$ sodium azide (prepared daily), and $100 \mu \mathrm{g}$ chlorophyll. Assays were illuminated and measured as above.

Whole-Chain (Water to MV) Measurements: Assay conditions were identical to those described for PSI measurements (Keck and Boyer, 1974) except that DCMU, DCIP, and sodium ascorbate were deleted from the medium.

Study Component: INHIBITION OF SOIL ENZYMATIC PROCESSES BY CHEMICAL SIMULANTS

Purpose: The effects of CEES on soil microbial and biochemical activities were evaluated in vitro by measuring the activity of two soil enzymes, dehydrogenase and phosphatase.

Desing and Incubation: Stock solutions of CEES (Aldrich Cat. No. 24264-0, Lot No. KM00903JM) were prepared in distilled water and added to samples of Palouse and Burbank silt loam soils (to final concentrations ranging from 0 to $250 \mu \mathrm{g} / \mathrm{g}$ dry soil) and incubated at $22^{\circ} \mathrm{C}$ in the dark. All dehydrogenase and phosphatase activities were measured in duplicate and mean values were compared with those of the control soil (not CEES-treated) and expressed as percent of those of the control.

\section{Experimental Methods:}

\section{Dehydrogenase Activity}

Soil samples were assayed for dehydrogenase activity as described by Tabatabai (1982) immediately following incubation and after 1 week and 4 weeks. Soils amended with CEES ( $1.5 \mathrm{~g}$ dry weight basis) were first mixed with $0.015 \mathrm{~g}$ of $\mathrm{CaCO}_{3}$; $0.3 \mathrm{ml}$ of $1 \%$ glucose and $0.25 \mathrm{~mL}$ of $3 \% 2,3,5$-triphenyltetrazolium chloride (TTC) and 
incubated for $24 \mathrm{~h}$ at $22^{\circ} \mathrm{C}$. Ten $\mathrm{mL}$ of methanol was then added to the soil and mixed thoroughly. The mixture was centrifuged and the absorbance of the supernatant at $485 \mathrm{~nm}$ was measured using a Beckman DU-50 spectrometer. Soil dehydrogenase activity, expressed as $\mathrm{mg}$ of $T \mathrm{TC}$-formazan produced per $\mathrm{g}$ of soil/24 $\mathrm{h}$, was quantified by comparing absorbance values to a standard curve prepared with reagent-grade TTC-formazan and methanol.

\section{Phosphatase Activity}

Soil phosphatase activity was measured on the CEES-amended soil using the procedure described by Tabatabai and Bremner (1969) as modified by Klein et al. (1979). One $\mathrm{g}$ of soil (dry weight) was placed in $15-\mathrm{mL}$ centrifuge tubes with $4 \mathrm{~mL}$ of modified universal buffer (MUB), which consists of tris(hydroxymethyl) amino methane, $3.025 \mathrm{~g}$; maleic acid, $2.9 \mathrm{~g}$; citric acid, $3.5 \mathrm{~g}$; boric acid, $1.57 \mathrm{~g} ; 1 \mathrm{~N} \mathrm{NaOH}$, $122 \mathrm{~mL}$ yielding final volume of $\mathrm{pH} 8.65$. One $\mathrm{mL}$ of para-nitrophenol phosphate ( $0.025 \mathrm{~N}$ prepared with MUB) was added to each tube. The tubes were stoppered, vortexed and incubated for $1 \mathrm{~h}$ at $37^{\circ} \mathrm{C}$. One $\mathrm{mL}$ of $0.5 \mathrm{~N} \mathrm{CaCl}_{2}$ and $4 \mathrm{~mL}$ of $0.5 \mathrm{~N}$ $\mathrm{NaOH}$ were then added to stop the reaction. The mixtures were centrifuged at 12,000 $\mathrm{g}$ for $10 \mathrm{~min}$, and supernatant absorbance was measured at $400 \mathrm{~nm}$ with a spectrophotometer. Phosphatase activity was determined by comparing these values to a standard curve constructed with reagent-grade para-nitrophenol and expressed as $\mu \mathrm{g}$ of para-nitrophenol released per $\mathrm{g}$ of soil/h. 



\subsection{REFERENCES}

Babich, H., Bewley, R. J. F., and Stotzky, G. 1983. "Application of the Ecological Dose Concept to the Impact of Heavy Metals on Some Microbe-Mediated Ecological Processes in Soil." Arch. Environ. Contam. Toxicol. 12:421

Cataldo, D. A., M. W. Ligotke, B. D. McVeety, H. Bolton, R. J. Fellows, S. M. Li, P. Van Voris, E. A. Crecelius, J. T. Hardy, and R. S. Wentsel. 1988. "Acute Environmental Toxicity and Persistence of CEES, A Chemical Agent Simulant: 2-Chioroethyl Ethyl Sulfide." PNL-6670, Pacific Northwest Laboratory, Richland, Washington.

Cataldo, D. A., M. W. Ligotke, B. D. McVeety, R. J. Fellows, S. W. Li, and P. Van Voris. 1989a. "Acute Environmental Toxicity and Persistence of BIS, a Chemical Agent Simulant: BIS, (2-Ethyihexyl) Phosphonate." U.S. Army Armament, Munitions \& Chemical Command, Aberdeen Proving Ground, Maryland.

Cataldo, D.A., S.D. Harvey, B.D. Mc Veety, R.J. Fellows, and P. Van Voris. 1989b. "Chemistry and Preliminary Environmental Effects of Mixtures of Triisopropyl Phospite, Bis-(2Ethylyhexyl)-Phosphonate, and Sulfur," U.S. Army Armament, Munitions \& Chemical Command, Aberdeen Proving Ground, Maryland.

Daubenmire, R. 1959. "A Canopy Cover Method of Vegetation Analysis." N.W. Sciences. 33:43-64.

Heller, S. R., and Milne, G. W. A. 1978. EPA/NIH Mass Spectral Data Base, Vol. 1, p. 280. U.S. Government Printing Office, Washington, D.C.

Howard, P.H., G.W. Sage, J.P. Robinson, and J. Jackson. 1985. "Environmental Fate Assessments of Chemical Agent Simulants and Decontaminants." SRC TR-85-194, U.S. Army AMCCOM, CRDC, Aberdeen Proving Ground, Maryland.

Keck, R. W., and J. S. Boyer. 1974. "Chloroplast Response to Low Leaf Water Potentials. III. Differing Inhibition of Electron Transport and Photophosphorylation." Plant Physiol. 53:474479.

Klein, D. A., et. al. 1979. "Role of Soil Microorganisms as Indicators and Possible Controlling Factors in Plant Succession Processes on Retorted Shale and Disturbed Soils." In: Rehabilitation Potential and Practice of Colorade Oil Shale Lands, C. W. Cook (ed.), Colorado State University, Fort Collins, Colorado.

Mathews, D. E., and Hayes, J. M. 1976. "Systematic Errors in Gas Chromatography-Mass Spectrometry Isotope Ratio Measurements." Anal.Chem. 48:1375-1382.

Pinkham, C.F.A., et al. Installation Environmental Impacts Assessment for United States Army. p B-6. Dugway Proving Ground. October 1977. (Updated March 1978).

Ramirez-Martinez, J. R. 1968. "Organic Phosphorus Mineralization and Phosphatase Activity in Soils." Folia Microbiol. 13:161.

Reinbold, C. A., Wentsel, R. S., Herricks, E. E., Kerster, H. W., and Shaeffer, D. J. 1986. "Environmental Hazard Ranking of Chemical Agent Simulants." In: U.S. Army Chemical Research. Development and Engineering Center Annual Scientific Meeting. November 1821, 1986. 
Skujins, J. 1976. "Extracellular Enzymes in Soil." CRC Crit. Rev. Microbiol. 4:383-421.

Tabatabai, M. A. 1982. "Soil Enzymes." In: Methods of Soil Analysis. Part2, (2nd Ed.), pp. 903-947, A. L. Page (ed.), American Society of Agronomy, Madison, Wisconsin.

Tabatabai, M. A., and J. M. Bremner. 1969. "Use of p-nitrophenylphosphate for Assay of Soil Phosphatase Activity." Soil Biol. Biochem. 1:301-307.

Van Voris, P., D. A. Cataldo, M. W. Ligotke, J. K. Fredrickson, S. W. Li, E. A. Crecelius, J. T. Hardy, R. J. Fellows, and R. S. Wentsel. 1987. "Acute Environmental Toxicity and Persistence of Selected Chemical Agent Simulants: DFP and DIMP." CRDEC-CR-87071. Chemical Research, Development and Engineering Center, Aberdeen Proving Ground, Maryland.

Van Voris, P., D. A. Cataldo, M. W. Ligotke, J. K. Fredrickson, S. W. Li, E. A. Crecelius, J. T. Hardy, R. J. Fellows, and R. S. Wentsel. 1989. "Acute Environmental Toxicity and Persistence of CEES, A Chemical Agent Simulant: 2-chloroethylethyl Sulfide." Chemical Research, Development and Engineering Center, Aberdeen Proving Ground, Maryland.

Walker, D. A. 1980. "Preparation of Higher Plant Chloroplasts." In: Methods in Enzymology Vol. 69, pp. 94-104, A. San Pietro (ed.), Academic Press, New York.

Zar, Jerrald H. 1974. Biostatistical Analysis. W. D. McElroy and C. P. Swanson (ed.), PrenticeHall, Inc., Englewood Cliffs, New Jersey. 


\title{
DISTRIBUTION
}

Offsite

\section{Copies}

1

Dr. Randall Wentsel

U.S. Army Chemical Research, Development and Engineering Center

SMCCR-RST-E

Bldg. E3220

Edgewood Area

Aberdeen Proving Ground, MD 21010-5423

2

DOE

Office of Scientific and Technical Information

\section{Onsite}

Copies

\author{
Dom Cataldo \\ Mike Ligotke \\ Harvey Bolton \\ Bob Fellows \\ Shu-mei Li \\ Peter Van Voris \\ Lee Rogers \\ Bill Pennell \\ Pat Hays \\ Technical Reports Files \\ Jim Falco \\ Publishing Coordination
}


